\title{
Crecimiento demográfico y dinámica social en El Salvador
}

\author{
Oscar Morales Velado
}

I. Parte: Antecedentes demográflcos salvadorenos. Evolución de la poblaclón en los siglos precedentes

El crecimiento de la población salvadorena en los siglos anteriores y en el presente, ha sido el resultado de la concurrencia de hechos sociales de tipo económico, político y cultural que en su acción conjunta han ido determinando la evolución de la población en distintas etapas, que han urdido formas de organización distintas de la vida social del pais.

Primera etapa: Impacto de la conqulsta y colonizaclón

Según estimaciones (Barón Castro, 227-239) la población salvadorefa en el período de la dominación colonial espanola presentó los siguientes vólumenes de población.

Cuadro N2 1

\begin{tabular}{|c|c|}
\hline Años & Habitantes \\
\hline 1524 & 130,000 \\
1551 & 60,000 \\
1570 & 77,000 \\
1778 & 146,000 \\
1796 & 161,000 \\
1807 & 200,000 \\
\hline
\end{tabular}

Fuente: Barón Castro, Rodolfo. La población en El Salvador. UCA editores, 1978.

El Salvador, págs.: 227-239. 
Las cifras de 1524 y 1551 muestran el descenso de la población amerindia salvadorena como consecuencia de la conquista y la dominación colonial de los primeros anos. De estas cifras se deduce una tasa negativa de crecimiento ( $-2.8 \%$ anual)'; lo que significa que aproximadamente 3 de cada-cien salvadorenos no tenia la probabilidad de sobrevivir al ano siguiente.

Estas dimensiones de la involución de la población salvadorena bosquejan la catástrofe demográfica que experimenta la población indígena del país. La explicación de este fuerte descenso no tiene como unico factor o causa las consecuencias inmediatas de la guerra de conquista, sino que a esta causa se asocian las modificaciones sustanciales que la población indígena soporta como consecuencia de la dominación colonial. Esas modificaciones ocurren en los más variados aspectos de la existencia social de los pueblos amerindios de EI Salvador; pero se destacan los cambios ocurridos en el sistema económico y en la implantación de un sistema político y cultural extrano y alienante para la población indigena. A continuación se harán breves consideraciones sobre la esencia de esas modificaciones y su impacto sobre los procesos demográficos.

Tal como to reconoce Browning2, el ecosistema salvadoreno prehispánico habia sido cultivado por el indigena bajo la concepción de interdependencia armoniosa entre el hombre y su medio, lo que conducia a una conservación y mejoramiento de ese medio ambiente. Con los asentamientos y prácticas económicas espanolas se modifica significativamente el paisaje de El Salvador y ello fue posible, por medio de la introducción del ganado - el cual deambulaba destruyendo cultivos y árboles- y en ese sentido de deterioro, se encauzó la reorganización agricola (desarrollo de cultivos de exportación) que fue marchando en detrimento de la producción económica de los cultivos que aseguraban la reproducción material de la población indigena.

En ese mismo sentido, la disminución de la población indígena, resulta explicable por las modificaciones en el sistema político y cultural. La introducción y desarrollo de la encomienda indiana, el repartimiento y otras formas de dominación político-cultural incidieron traumáticamente en las generaciones de adultos indigenas que habian sido socializados con valores y patrones de comportamiento opuestos a los que implanta la dominación espanola. La percepción indigena de experimentar la dominación y destrucción de su ser cultural incidió de modo desalentador en la reproducción biológica, económica y cultural de su existencia como etnia.

Al desarrollarse y consolidarse la dominación colonial, la población 
salvadorena fue moditicando su composición étnica, a grado tal que la población mestiza fue adquiriendo una proporción considerable. Sin embargo, los princlaples asentamientos de población que constituirlan a la posteridad las principales bases demográficas del pals, se fundaron a partir de los pueblos pipiles, lencas, pocomames y chortles que existlan desde épocas pre-hispánicas. La fundación de pueblos, villas y ciudades espanolas partieron de esas bases de población indigena, las cuales eran indispensables para el expollo económico y la dominación polltico-cultural, por ello no resulta extrano que 127 de 262 municipios existentes en el pals hayan sido fundados en el siglo $X V I^{3}{ }^{3}$ sobre la base de población indlgena pre-existente.

La recuperación del volumen de la población salvadorena en los siglos posteriores de la dominación colonial ocurrió en unos escenarios distintos, perfilados por las nuevas estructuras y sistemas económicos, polfticos y culturales; todo ello sobre una base étnico-biológica distinta: el mestizaje.

Asimismo, las modificaciones poblacionales implicaron movimientos migratorios y crecimientos de población en zonas de diferente importancia demográfica; significando auge o decadencia para muchos de los tradicionales centros poblados, para el caso, la importancia demográfica de los pueblos indígenas de la zona sur-occidental del país (Sonsonate y Ahuachapán) fue notable durante los siglos XVI y XVII, mientras se sostuvo la reproducción ampliada de los cultivos de cacao y bálsamo, desarrollados por la poblacion indígena y aprovechados $\mathrm{co-}$ mercialmente por mercaderes espanoles. ${ }^{4}$ Aunque esto no significo que dichos cultivos se hayan desarrollado exclusivamente en la zona occidental del pais, ya que por el contrario, el cultivo del cacao se desarrolló de modo general en todo el pais.

Para el siglo XIX, la importancia económico-social de esos cultivos habia decaido y en consecuencia, habia disminuido la importancia demográfica de muchos centros poblados indigenas que se habian desarrollado sobre esá base económica.

El desarrollo de la dominación colonial española fue acentuando la hegemonia del capital comercial sobre las instituciones o formas de producción en los espacios económicos del pais. En la reorganización económica-colonial comienza a destacarse la importancia de las actividades de agro-exportación, especialmente de anil y sobre la base unas relaciones sociales de producción afincadas en formas privadas de tenencia de la tierra; la hacienda (parcialmente de exportación), encabezaba las formas principales de las relaciones de producción agricola en los siglos XVIII y XIX. 
Estas unidades económicas se convierten en los nuevos polos de la dinámica de la población salvadorena.

Desde finales del siglo XVIII hasta mediados del siglo $X \mid X$, la dinámica de la población salvadorena fue Impulsada, en lo económico, por el desarrollo de las zonas anileras del pais, las cuales se ubicaban en las zonas central y norte. Examinando las cifras de población por departamento, que presenta Barón Castro, construidas en base al informe de Córtez y Larraz, en su "descripción geográfica y moral de la Diócesis de Guatemala"b, se puede observar la importancla demográfica relativa que tienen los departamentos con zonas dedicadas a la producción anilera de exportación, en esa época; el Cuadro $\mathbf{N}^{2} 2$, ilustra estadisticamente esa situación.

\section{Cuadro № 2}

El Salvador: poblaclón según departamentos, 1978

\begin{tabular}{|c|c|c|c|}
\hline & Departamento & Habitantes & Vabr relativo (\%) \\
\hline $\begin{array}{l}\text { No } \\
\text { Anileros }\end{array}$ & $\begin{array}{l}\text { Ahuachapán } \\
\text { Sonsonate } \\
\text { Santa Ana } \\
\text { La Libertad } \\
\text { San Salvador } \\
\text { Cuscatlán } \\
\text { La Paz } \\
\text { Usulután }\end{array}$ & $\begin{array}{l}26,537 \\
35,262 \\
57,124 \\
30,881 \\
48,235 \\
36,557 \\
27,730 \\
28,266\end{array}$ & $\begin{array}{r}5.5 \\
7.3 \\
11.8 \\
6.4 \\
10.0 \\
7.6 \\
5.7 \\
5.9\end{array}$ \\
\hline \multirow[t]{3}{*}{ Anileros } & $\begin{array}{l}\text { Sub-total } \\
\text { Chalatenango } \\
\text { Cabanas } \\
\text { San Vicente } \\
\text { San Miguel } \\
\text { Morazán } \\
\text { La Unión }\end{array}$ & $\begin{array}{l}290,592 \\
48,558 \\
23,213 \\
29,218 \\
44,404 \\
24,147 \\
22,290\end{array}$ & \begin{tabular}{r|}
60.2 \\
10.1 \\
4.8 \\
6.1 \\
9.2 \\
5.0 \\
4.6
\end{tabular} \\
\hline & Sub-Total & 191,830 & 39.8 \\
\hline & Total & 482,422 & 100.0 \\
\hline
\end{tabular}

Fuente: Barón Castro, Op. c. cit. pág. 484 
Para 1878, momento que puede considerarse como el final de la época anilera, los departamentos con un predominio en ese cultivo de exportación, representaban el $\mathbf{4 0 \%}$ (aproximado) de la población del país, cifra que resulta muy indicativa de la esencia de la hacienda anilera sobre las otras formas de producción, entre las que se encontraban los cultivos de consumo nacional desarrollados bajo formas comunal-indigenas y ejidales.

En términos de una comparación retrospectiva, los seis departamentos anileros senalados en el cuadro anterior, sumaban para 1770, una población de 26,947 habitantes, equivalente al $20.4 \%$ de la población total del pais, al inicio de la época anilera; la duplicación de las cifras relativas de la población de esos departamentos en toda esa época, denota la influencia de los procesos económico-sociales en el crecimiento de la población. Una representación gráfica lineal de esas variaciones relativas ilustra mejor las magnitudes de los crecimientos:

\section{Gráfica N 1}

varlaclones relativas de la poblaclón en los dejartamentos de El Salvador, perlodo: 1770 - 1878

$\%$

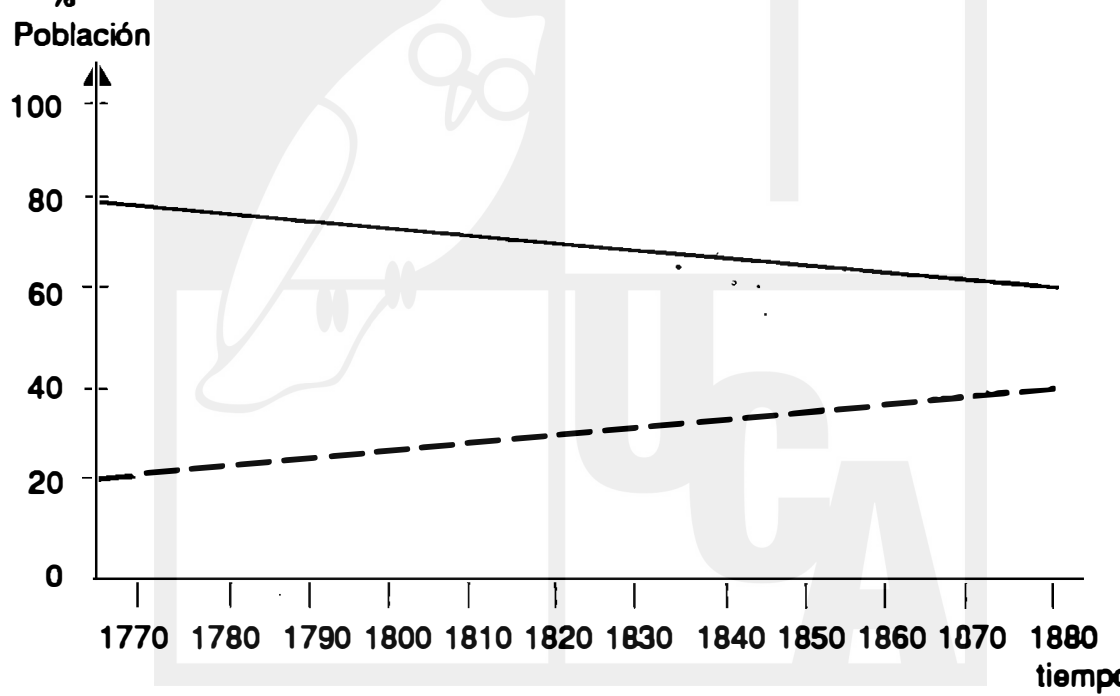

Departamento no-ah́ileros

- - Departamentos añileros 
La tendencia histórica demográfica, apunta, para ese periodo, hacia una reorganización y crecimiento demográfico del pais en torno a las zonas agrícolas de exportación anilera. Una confirmación más analítica de esa tendecia, se muestra con el examen de las tasas de crecimiento anual que aparecen en el cuadro siguiente:

\section{Cuadro N2 3}

El Salvador: tasas de creclmlento anual dela población de los departamentos, perlodo: 1770 - 1878

\begin{tabular}{|c|c|c|}
\hline & Departamento & $\begin{array}{c}\text { Tasa de crecimiento }\left({ }^{*}\right) \\
\text { anual }(\%)\end{array}$ \\
\hline \multirow[t]{2}{*}{$\begin{array}{l}\text { No } \\
\text { Anileros }\end{array}$} & $\begin{array}{l}\text { Ahuachapán } \\
\text { Sonsonate } \\
\text { Santa Ana } \\
\text { La Libertad } \\
\text { San Salvador } \\
\text { Cuscatlán } \\
\text { La Paz } \\
\text { Usulután }\end{array}$ & $\begin{array}{l}1.23 \\
0.63 \\
1.54 \\
1.80 \\
0.55 \\
1.03 \\
0.41 \\
1.19\end{array}$ \\
\hline & Sub-total $\overline{(\bar{X})}$ & 1.05 \\
\hline \multirow[t]{3}{*}{ Aneleros $<$} & $\begin{array}{l}\text { Chalatenango } \\
\text { Cabanas } \\
\text { San Vicente } \\
\text { San Miguel } \\
\text { Morazán } \\
\text { La Unión }\end{array}$ & $\begin{array}{l}2.05 \\
2.43 \\
1.79 \\
1.90 \\
1.26 \\
1.73\end{array}$ \\
\hline & Sub-total $(\bar{X})$ & 1.96 \\
\hline & Total nacional & 1.20 \\
\hline
\end{tabular}

Fuente: Barón Castro, Op. cit. págs. 239 y 484.

(") Las tasas de crecimiento anual se estimaron en base a tórmula de crecimiento geométrico de la población.

$$
r=\sqrt[V]{\frac{N^{2}}{N^{0}}}-1
$$


Las cifras del cuadro anterior confirman que el promedio de crecimiento anual en los departamentos no-añileros era de una persona por cada cien habitantes; mientras que en los departamentos con producción anilera el crecimiento naual era a razón de 2 personas (aproximadamente) por cada cien habitantes.

\section{Mapa $N^{2} 1$ \\ Producclón de afll, 1807-60}

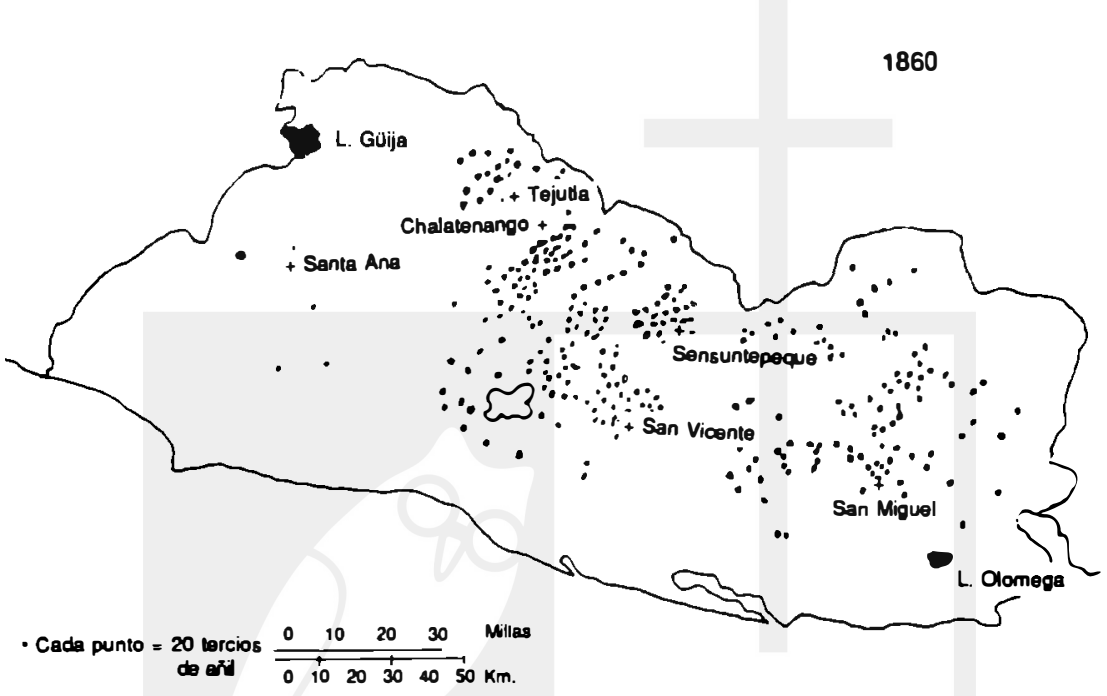

Fuente: Browning, David. "E Salvador, la tierra y el hombre". Ministerio de Educación, San Salvador, 1975. (Mapa 17).

Desde una perspectiva de interés socio-demográfica, resulta importante senalar que la mayor parte de la producción anilera se desarrollaba en haciendas grandes y medianas, lo cual de acuerdo al tipo de relaciones socio-económicas como aparcerias, colonato y otras formas de relación económico-social pre-capitalistas, permitia retener población en las haciendas anilera.s Así mismo, los procesos de concentración de población en centros urbanos en los que se comercializaba la producción anilera y otro tipo de productos, fueron muy significativos para el crecimiento en el volumen de la población de los llamados departamentos anileros.

El crecimiento demográfico en esos departamentos resulta explicable, tanto por la via del crecimiento natural o vegetativo de la po- 
blación como por la via del incremento migratorio. El primer tipo de crecimiento, significa un aumento y sostenimiento de la fecundidad, muy por encima de los niveles de mortalidad; este crecimiento natural de la población se vió alentado por la existencia de formas de organización económica que ofrecian condiciones de reproducción material para las nuevas generaciones. El crecimiento por inmigración, resulta explicable en términos de atracción u orientación de las migraciones hacia departamentos anileros, por la imagen económica y cultural que proyectaban tales zonas y en términos de las condiciones que causan la emigración, se puede formular la hipótesis de la escasez relativa de tierras o el desarrollo de procesos y estructuras de concentración de la tierra, que van generando condiciones de una sobre-población relativa en las zonas no-anileras.

La evolución de la población salvadorena en toda la etapa de la dominación colonial, se manifiesta primero como un fuerte descenso de la población indígena, lo cual como ya se ha dicho en otros témrinos, fue debido a la desintegración de las formas de organización económica, política y cultural de las sociedades indigenas. A medida que se introducen nuevas instituciones sociales y se integran más o menos modificando a las instituciones pre-existentes, la sociedad va generando una estabilidad en sus mecanismos de reproducción económica y humnana, como puede apreciarse en el gráfico $N^{2} 2$.

A partir de 1570 a 1770, el crecimiento de la población salvadorena es de tipo sostenido de carácter lineal; pero a partir de las últimas décadas del siglo XVIII, el crecimiento de la población describe formas de crecimiento geométrico o exponencial.

La hipótesis que explica esa modificación en el patrón de reproducción de la población salvadorena, consiste en la nueva reorganización de la vida económica y cultural que se genera con el auge de la producción anilera del último periodo colonial. Efectivamente, el auge de la producción anilera demandaba fuertes contingentes de población, tanto en su producción estrictamente agrícola como en los obrajes; así mismo, la producción anilera demandaba insumos y otros bienes, activándose todas las estructuras económico y sociales del pais y propiciando con ello, incentivos sociales para la reproducción o mayor fecundidad de la población salvadorena.

\section{Segunda etapa: La formaclón de la socledad naclonal}

La independencia política de las provincias de Centro América de la dominiación colonial espanola, no signifioo inmediatamente la formación de los Estados nacionales; estos surgieron después de un largo pro- 


\section{Gráflco № 2}

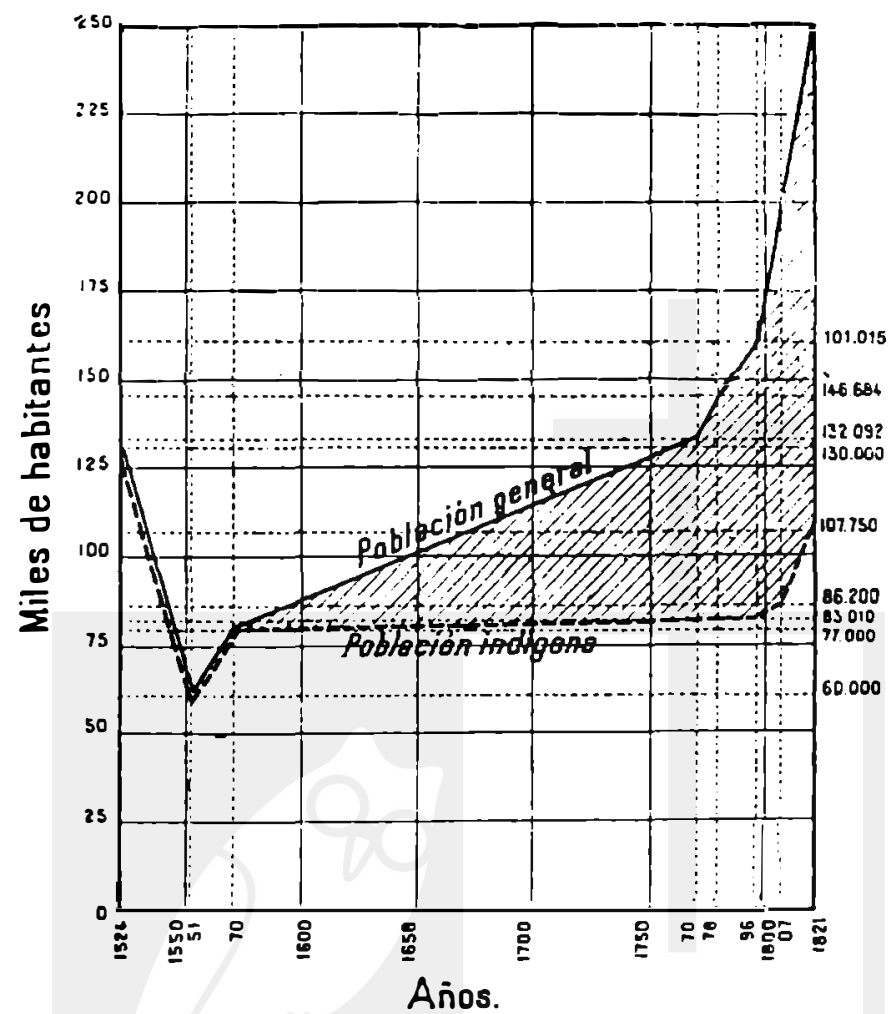

Cuedro que representa el desarrollo de la población salvedoreña entre 1524 y 1821 .

Fuento: Barón Castro. Rodolfo. La población de EI Salvador, UCA Editores, 1978, pág. 295

ceso, en el que se reestructuraria un nuevo aparato productivo con los circuitos correspondientes de comercialización y no sin un establecimiento y definición de las lealtades nacionales. Dados esos procesos, se considera con bastante acierto que la formación real (es decir económico-social y política) de los estados centroamericanos ocupó la historia del siglo pasado y algunas décadas del presente siglo.

En este marco histórico, la población salvadorena observó los volúmenes de población que aparecen en el cuadro siguiente: 
Quedro NP 4

El Savedor: pobleción salvedorana en el slglo XIX

\begin{tabular}{|l|c|c|}
\hline Antos & Volumen de población & $\begin{array}{c}\% \\
\text { Tasa de (1) } \\
\text { Crecimionto (Y) }\end{array}$ \\
\hline 1821 & 250,000 & \\
1855 & 394,000 & 1.34 \\
1878 & 554,000 & 1.49 \\
1882 & 612,943 & 2.56 \\
1887 & 664,513 & 1.62 \\
1892 & 703,000 & 1.13 \\
1899 & 758,945 & 1.09 \\
\hline
\end{tabular}

Fuento: Barón Castro, Op. cit., pág. 493.

$$
r=\sqrt[t]{\frac{N^{N}}{N^{0}}}-1
$$

Los volumenes de población y las respectivas tasas de crecimiento anual del cuadro anterior, permiten advertir dos periodos en el crecimiento de la población salvadorena, durante el siglo pasado. El primer período se puede cifrar a partir de 1821 y cuya terminación llegó en los primeros anos de la década de los ochentas del siglo pasado; durante este período se observó una tendencia a la elevación de las tasas de crecimiento de la población de $\mathbf{1 . 3 4 \%}$ a $2.56 \%$ (valor máximo).

Esta velocidad creciente de la población salvadorena en ese periodo, estuvo asociada a la superación de la inestabilidad política que sobrevino en los primeros anos de independencia y que contó siempre con una base económico social afincada en la producción de agroexportación (anilera) y también con una producción destinada a las necesidades nacionales que se desarrollaba en tierras ejidales, comunales-indigenas y en parcelas privadas. Este tipo de organización económica agricola permitió una reproducción creciente de la población salvadorena. Pero a medida que la producción anilera fue perdiendo importancia y por el contrario, la producción cafetalera fue incrementando, se fue dando un proceso de concentración de tierras en función de la mejor rentabilidad de la producción de café. Este proceso implicó una reorganización no sólo del aparato productivo agrícola, sino de la matriz de relaciones de producción, en la cual, las formas de propiedad privada van ganando hegemonia, en detrimento de las formas de 
propiedad comunal y pública, las que en ültima instancia desaparecieron. Según estimaciones de Menjivart, los terrenos ejidales, las tierras de las comunidades indigenas y otras formas pre-capitalistas constituian no menos del $\mathbf{4 0} \%$ del territorio nacional.

La fuerte proporción de tierras explotadas bajo formas precapitalistas, dá una idea del impacto tremendo que significos el desaparecimiento de los ejidos y de las tierras comunales indígenas, en las últimas décadas del siglo pasado. Esta reorganización agricola cafetalera conllevó a una disminución sustancial de los recursos de subsistencia y de los bienes agricolas que en general, eran destinados para el consumo nacional. Amón de la inestabilidad económica, ésta se vio asociada a formas de inestabilidad política y cultural, las cuales se constituyeron en factores desalentadores para la elevación de los niveles de reproducción humana en el pais. De alli que a partir de 1882 a 1899 , se observaron cada vez tasas de crecimiento poblacional menores (r), explicables demográficamente tanto por la disminución de la fecundidad y/o aumento en los niveles de mortalidad), como por el aumento de las emigraciones a paises vecinos.

\section{Parte. La dinámica soclal y demográflca en la primera mitad del siglo XX.}

La reorganización económica, política y cultural de la sociedad salvadorefa iniciada en el siglo pasado, se fue estabilizando en sus nuevas estructuras en las primeras décadas del presente siglo, lo cual implicos una nueva distribución espacial de la población salvadorena. Esta distribución resulta explicable por las hipótesis siguientes: 1a.) con la consolidación del modelo social agro-exportador, se generaron polos de crecimiento demográfico alrededor de las zonas cafetaleras por ello, los principales centros de asentamiento poblacional del país se constituyeron en la franja meridional, lo cual coincide con las zonas principales de desarrollo de ese cultivo y como puede notarse en el mapa No. 2.

Según estimaciones de Castro', la población urbana y rural de algunos municipios se detalla en el cuadro siguiente:

Es de notar como la población de las zonas de mayor desarrollo cafetalero tuvieron tasas de crecimiento $(r)$ muy elevadas, en algunos casos superiores al 2 por ciento anual; entre ellas destacan San Salvador, Coatepeque, Santa Tecla. También en el mismo cuadro aparecen zonas que no cultivaban café de modo fundamental y que sin embargo, muestran tasas de crecimiento poblacional elevadas, to cual puede resultar explicable por convertirse estas zonas en receptoras de 


\section{Mapa $\mathbf{N}^{2} 2$ \\ Zonas cafetaleras}

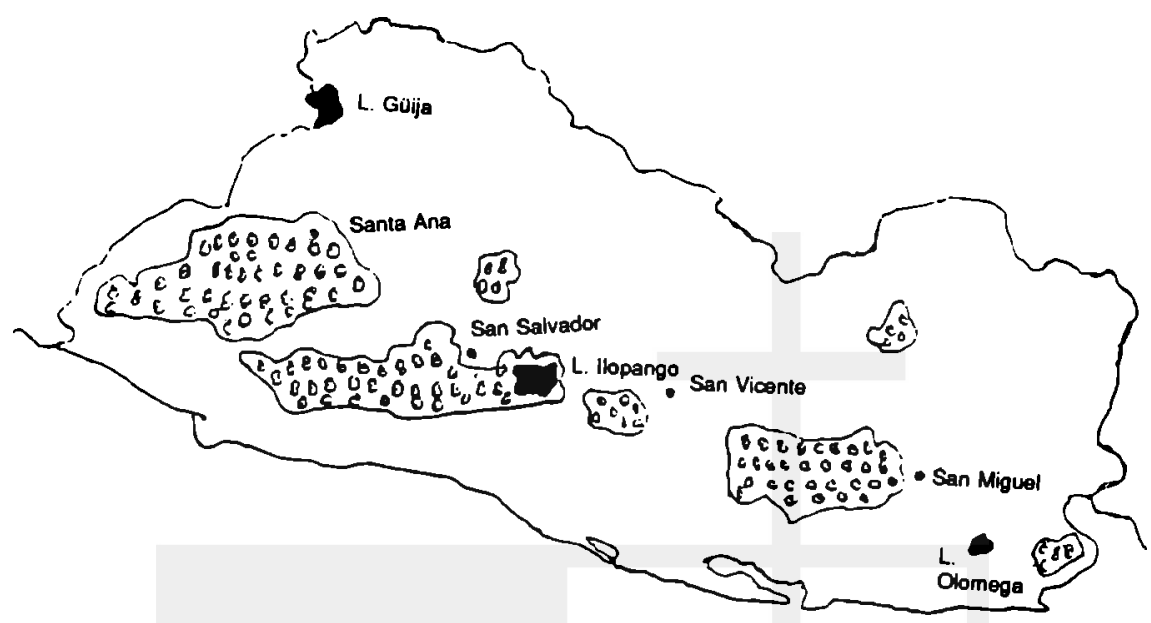

Fuente: Browning, David. "El Salvador, la tierra y el hombre". Ministerio de Educación. San Salvador, 1975. (Mapa 16).

\section{Cuadro Ne 4-A}

Poblaclón en algunos munlclplos de El Salvador, 1905 y 1925

\begin{tabular}{|l|c|c|c|}
\hline Municipios & $\begin{array}{c}\text { Población en } \\
1905\end{array}$ & $\begin{array}{c}\text { Población en } \\
1925\end{array}$ & $\begin{array}{c}\text { Tasa de } \\
\text { crecimiento }(r) \%\end{array}$ \\
\hline San Salvador & 50,304 & 86,427 & 2.9 \\
Santa Ana & 50,854 & 73,802 & 1.9 \\
-San Miguel & 25,462 & 36,606 & 1.8 \\
San Vicente & 21,048 & 33,020 & 2.3 \\
-Zacatecoluca & 18,480 & 32,701 & 2.9 \\
Chalchuapa & 20,856 & 29,913 & 1.8 \\
Santa Tecla & 17,528 & 28,088 & 2.4 \\
Coatepeque & 13,704 & 22,455 & 2.5 \\
-Sensuntepeque & 12,960 & 21,372 & 2.5 \\
Metapán & 12,984 & 20,705 & 2.4 \\
Suchitoto & 16,688 & 20,439 & 1.04 \\
Ilobasco & 11,328 & 20,168 & 2.9 \\
\hline
\end{tabular}


migrantes latentes que al verse desabjados de sus cultivos de subsistencia por el auge de la producción cafetalera, optaban por ocupar zonas de vocación no-cafetalera; este puede ser el caso de Zacatecoluca.

2a.) El proceso de concentración de tierras asociado al auge de la producción cafetalera y a la disminución de tierras que aseguraban la producción de bienes destinados a satisfacer las necesidades básicas de las mayorias de la población, propició fenómenos migratorios masivos hacia zonas de menor fertilidad, especialmente la franja norte del pais e inclusive llevó al poblamiento de las tierras del sur de Honduras.

Esto significó un alcance relativo de las fronteras agricolas del pais, las cuales se acotarian posteriormente en la década de los anos cincuenta y sesenta, con algún control de la malaria y de los pantanos, al desarrollarse masivamente el cultivo del algodón en los valles costeros de las tierras del sur del pais.

3a) En estrecha relación al contenido de la primera hipótesis, puede sustentarse que también el desarrollo demográfico observado desde finales del siglo pasado y durante toda la primera mitad del siglo presente giró en torno de aquellos departamentos, cuyos centros urbanos además de estar enclavados en zonas cafetaleras, se constituyeron en ejes de la nueva estructuración política y cultural de la sociedad nacional. Hay pues, una sinergia de factores económicos, políticos y culturales que inciden en el crecimiento demográfico heterogéneo del pais.

En abono o fundamentación empirica de estas hipótesis, se presenta a continuación una exposición analítica de datos. Las comparaciones de volúmenes de población por departamento a principios de siglo y al final de la tercera década del mismo, apuntaban hacia una estructura poblacional con mayor peso en las zonas cafetaleras.

En efecto y, según Browning', "Las plantaciones de café a gran escala tienen su medio ideal en los suelos bien drenados, básicos, alcalinos y fértiles que hay a lo largo del pié de los cerros y de las laderas superiores de las tierras volcánicas centrales de altura. En un principio hubo una concentración a lo largo de estas tierras altas alrededor de Santa Ana, Sonsonate, Ahuachapán, Santa Tecla y San Salvador y más tarde hacia el oeste de San Vicente y en las laderas del somplejo volcánico cuyo centro es el volcán de San Miguel". La referencia anterior justifica la clasificación de los volúmenes de población entre los departamentos con zonas cafetaleras y aquellos que no poseen significativamente dichas zonas. 
En el cuadro siguiente aparece el detalle de la distribución de frecuencias de la población salvadorena, en el período 1892 - 1930.

Cusdro $\mathrm{NP} 5$

El Salvedor: valores cbeolutos y relatlvos de la poblackon sogún departamemtos 1892 y 1930

\begin{tabular}{|c|c|c|c|c|c|}
\hline \multirow{3}{*}{$\begin{array}{l}\text { Clasifi- } \\
\text { cación }\end{array}$} & \multirow{3}{*}{ Departamentos } & \multicolumn{4}{|c|}{ Habitantes } \\
\hline & & \multicolumn{2}{|c|}{1982} & \multicolumn{2}{|c|}{1930} \\
\hline & & Absoluta & $\begin{array}{c}\text { Relativa } \\
(\%)\end{array}$ & Absoluta & $\begin{array}{l}\text { Relativa } \\
(\%)\end{array}$ \\
\hline \multirow[t]{2}{*}{$\begin{array}{l}\text { Zonas } \\
\text { más } \\
\text { cafeta- } \\
\text { leras }\end{array}$} & $\begin{array}{l}\text { 1. Ahuachapán } \\
\text { 2. Sonsonate } \\
\text { 3. Santa Ana } \\
\text { 4. La Libertad } \\
\text { 5. San Salvador } \\
\text { 6. San Miguel }\end{array}$ & $\begin{array}{l}37,000 \\
41,000 \\
80,000 \\
49,000 \\
63,000 \\
60,000\end{array}$ & $\begin{array}{r}5.3 \\
5.8 \\
11.3 \\
7.0 \\
8.9 \\
8.5\end{array}$ & $\begin{array}{r}80,024 \\
100,896 \\
154,663 \\
119,178 \\
191,320 \\
128,048\end{array}$ & $\begin{array}{r}5.6 \\
7.0 \\
10.8 \\
8.3 \\
83 \\
13.3 \\
8.9\end{array}$ \\
\hline & Sub-Total & 330,000 & 46.8 & 774,129 & 53.9 \\
\hline \multirow[t]{3}{*}{$\begin{array}{l}\text { Zonas } \\
\text { menos } \\
\text { cafeta- } \\
\text { leras }\end{array}$} & $\begin{array}{l}\text { 1. Chalatenango } \\
\text { 2. Cuscatlán } \\
\text { 3. Cabañas } \\
\text { 4. San Vicente } \\
\text { 5. La Paz } \\
\text { 6. Usulután } \\
\text { 7. Morazán } \\
\text { 8. La Unión }\end{array}$ & $\begin{array}{l}54,000 \\
62,000 \\
35,000 \\
40,500 \\
70,000 \\
42,000 \\
35,000 \\
35,000\end{array}$ & $\begin{array}{l}7.7 \\
8.8 \\
5.0 \\
5.8 \\
9.9 \\
6.0 \\
5.0 \\
5.0\end{array}$ & $\begin{array}{r}82,298 \\
83,653 \\
58,611 \\
77,534 \\
88,229 \\
124,859 \\
75,013 \\
73,285\end{array}$ & $\begin{array}{l}5.7 \\
5.8 \\
4.1 \\
5.4 \\
6.1 \\
8.7 \\
5.2 \\
5.1\end{array}$ \\
\hline & Sub-Total & 373,000 & 53.2 & 663,482 & 46.1 \\
\hline & Total & 703,500 & 100.0 & $1,437,611$ & 100.0 \\
\hline
\end{tabular}

Fuent: Barón Castro, R. Op. cit. págs. 488 y 508.

Es de notar como en 1892 los departamentos con zonas cafetaleras tenían una población inferior al $50 \%$ y para 1930 , esos departamentos tenían la mayor parte de la población del país. 
Así mismo, cabe mencionar que algunos departamentos considerados originalmente como no-cafetaleros como San Vicente y Usulután, paulatina y posteriormente, van desarrollando zonas con ese cultivo. EI promedio de crecimiento anual de la población de los departamentos fundamentalmente cafetaleros, en el período de 1892-1930 fue de $2.71 \%$; en tanto que la correspondiente medida de crecimiento de la población de las zonas cafetaleras era el doble respecto a las otras zonas del país (ver Anexo No. 1).

La consolidación del modelo agro-exportador cafetalero asociado a la reorganización político social del país en el período 1892-1930, le imprimió una nueva dinámica al crecimiento de la población; de tasas cercanas al $1.0 \%$ que se observaban en el reacomodo económico y social de finales del siglo pasado, a niveles de crecimiento poblacional superiores al $2 \%$, en la tercera década del presente siglo. El análisis de estos datos permiten plantear la tesis de que el crecimiento de la población salvadorena en este siglo está condicionado fuertemente por la consolidación y expansión del modelo agro-exportador cafetalero, que al desarrollarse con bajos niveles de inversión en equipos, en maquinaria y en tecnologia, ha utilizado grandes volúmenes de fuerza de trabajo, en condiciones de un mercado de trabajo con una oferta de trabajadores muy superior a la demanda y por medio del cual, se han mantenido niveles salariales bajos, que han contribuido al mantenimiento de una rentabilidad promedio como situación estímulo para la expansión del mismo cultivo. Para el funcionamiento del sistema de producción cafetalero, en las condiciones de competencia y dependencia hacia un mercado internacional, ha sido fundamental disponer de una población abundante y que permanentemente se rejuvenece, $b$ cual ha permitido niveles salariales bajos $\infty$ n niveles de productividad máxima, al mismo tiempo.

La reproducción de la fuerza de trabajo que ha demandado el modelo agro-exportador se ha desarrollado en un sector de relaciones sociales subordinado al sector agro-exportador y bajo formas de producción campesina, colonato y otras formas "pre-capitalistas, que han logrado sobrevivir de ese modo a la expansión de los cultivos de exportación.

La expansión de la producción cafetalera desarrollada fundamentalmente como una ampliación de tierras dedicadas a ese cultivo (expansión rentística) constituye el indicador de uno de los factores más significativos en la explicación del crecimiento de la población salvadorena durante este siglo.

Los datos disponibles de superticie cultivada de café, para el primer 
tercio de este siglo, aparecen a continuación.

Cuadro Ne 6
Area cultlvada de caf́́. El Salvador, 1921-1933

(En hectáreas)

\begin{tabular}{|c|c|c|}
\hline Ano & Area cultivada & $\begin{array}{c}\text { Tasa de crecimiento anual de Ha. } \\
(\mathbf{r}) \%\end{array}$ \\
\hline 1921 & 57,000 & 12.4 \\
1924 & 81.000 & 2.0 \\
1931 & 93,000 & 2.0 \\
\hline
\end{tabular}

Fuente: Guldos Vojar, R. Op. cit. pág. 102

La tasa de crecimiento anual de la superticie sembrada de café, medida en héctareas para el periodo 1921-1931 es igual al 5\% y la tasa de crecimiento de la población en las zonas o departamentos cafetaleros era $2.7 \%$ en el periodo 1892-1930; ésta comparación confirma un sentido positivo en la relación de crecimiento de ambas series (tierras dedicadas al café y población).

En to referente al sistema socio-cultural que se desarrolla desde el siolo pasado, en países de América Latina y particularmente en EI Salvador, la agricultura de exportación consolida instituciones sociales como la hacienda y el colonato que en su reproducción histórica y social generan una serie de valores necesarios a la pervivencia de tales instituciones; entre esos rasgos culturales y sociales destacan: el patriarcalismo, el patrimonialismo y el machismo como rasgos característicos en las familias de los propietarios de haciendas. Esos rasgos culturales asimilados como ideales y patrones de comportamiento por los campesinos y las mayorias sociales del pais, contribuyeron a la reproducción del machismo así como a la reproducción acelerada de la población misma.

En el período 1930-1950, el crecimiento de la población salvadorena se vió desacelerado, ya que su tasa de crecimiento fue de $1.5 \%$ anual, cifra inferior al crecimiento póblacional observado en el primer tercio de este siglo (1.9\%).

Esta disminución en la velocidad de reproducción de la población salvadorena resulta explicable por la confluencia de fenómenos económicos y políticos en las dos décadas que preceden a la mitad de esta centuria. En este orden de ideas, destaca la crisis en la pro- 
ducción cafetalera que duró toda la década de los treinta y que dada la conformación dependiente de la economla salvadorena, dicha situación influyó notablemente en el descenso de los niveles de empleo.

El descenso en la tasa de crecimiento de la población en el periodo 1930-1950, se encuentra pues, asociado a la recesión económica mundial, especialmente por la dependencia de la economla cafetalera salvadorefia a los centros hegernónicos internacionales. La crisis económica del país que sobrevino a la calda de los precios del café, agudizó el problema del desempleo y la miseria de los trabajadores de las zonas rurales, especialmente en las zonas cafetaleras; los datos del valor y precio de las exportaciones ilustran la magnitud de esta crisis.

\section{Cuadro $\mathbf{N}^{2} 7$}

El Salvador: valor (en §) y preclo del quintal en las exportaciones de café, en el periodo: 1929-1935

\begin{tabular}{|c|c|c|}
\hline Ano & Valor en & Precio qq (屯) \\
\hline 1929 & 84090450 & 33.52 \\
1930 & 23914481 & 18.75 \\
1931 & 21695441 & 18.27 \\
1932 & 12867077 & 14.92 \\
1933 & 19512556 & 15.97 \\
1934 & 22824125 & 21.05 \\
1935 & 24228376 & 22.26 \\
\hline
\end{tabular}

Fuente: Guidos Vejar, Rafael. Op. cit. págs. 102.

Los fenómenos económicos asociados a fenómenos de tipo político como la insurrección y represión del levantamiento campesino en 1932, propiciaron flujos migratorios de salvadorenos hacia paises de la región centroamericana.

El desempleo y los fenómenos poliicos aludidos tuvieron un impacto mayor en zonas cafetaleras, especialmente en departamentos de la zona occidental del pals, no obstante, que en todos los departamentos se observó una disminución en el ritmo de crecimiento poblacional; en Ahuahapán y Sonsonate, dos de los departamentos más afectados, la velocidad de crecimiento de la población se redujó a la mitad del promedio observado de 1892 a 1930 (ver Anexo № 1).

En los anos posteriores a la Segunda Guerra Mundial se observó un 
crecimiento mayor en la demanda y los precios internacionales del café y en consecuencia, las csrisis económicas y políticas del pais y, su incidencia en los fenómenos demográficos comenzaron a ceder; para ir consolidando asi los mecanismos del funcionamiento económico, político y poblacional del sistema de reproducción dependiente.

La relación de fenómenos de tipo económico como precios internacionales del café y superticie cultivada y sus implicaciones en el tipo de crecimiento poblacional, denotan la existencia de una estructura social generadora de una determinada correlación de fenómenos. Para el caso, la situación intemacional del mercado y precios del café, a finales del siglo pasado constituyó la situación condicionante para que se estructurara un modelo económico agro-exportador dependiente y a partir de entonces, se fue observando un crecimiento en el volumen de tierras dedicadas a ese cultivo; si bien la correlación entre precios internacionales del café y superficie cultivada no es muy alta, fundamentalmente debido a que el café es un cultivo más o menos permanente y por lo tanto, las variaciones de precios no son muy sensibles en términos de superficie cultivada, si puede considerarse como hipótesis que las variaciones en los precios si tienen una correlación importante con los incrementos en la superficie cultivada, es decir con la velocidad de expansión de la renta agricola cafetalera. En el cuadro siguiente se presentan datos que siven de base empirica para la sustentación de estas hipótesis.

Cuadro № 8

El Salvador: preclos del caf́́ y superficle sembrada

\begin{tabular}{|c|c|c|c|c|c|}
\hline Año & $\begin{array}{c}\text { Precio qq } \\
\text { (c) } \\
\text { (a) }\end{array}$ & $\begin{array}{c}\text { Indice de } \\
\text { precio } \\
\text { (b) }\end{array}$ & $\begin{array}{c}\text { Sueprticie } \\
\text { sembrada } \\
\text { (héctareas) } \\
\text { (a) }\end{array}$ & $\begin{array}{c}\text { Indice de } \\
\text { superficie } \\
\text { sembrada }\end{array}$ & $\begin{array}{c}\text { Diferencias } \\
\text { incremento } \\
\text { superficie } \\
\text { sembrada }\end{array}$ \\
\hline 1931 & 18.27 & $49.1 \%$ & 93,000 & $100.0 \%$ & 0 \\
1933 & 15.97 & $42.9 \%$ & 95,000 & $102.0 \%$ & $2 \%$ \\
1945 & 37.24 & $100.0 \%$ & 110,400 & $118.7 \%$ & $18.7 \%$ \\
1948 & 69.02 & $185.3 \%$ & 129,100 & $138.8 \%$ & $36.8 \%$ \\
1951 & 132.77 & $356.5 \%$ & 113,100 & $121.6 \%$ & $21.5 \%$ \\
1954 & 146.20 & $392.6 \%$ & 119,600 & $128.6 \%$ & $28.6 \%$ \\
\hline
\end{tabular}

(a) Dada Hirezi. Héctor Op. cit. pág. 32

(b) Tomando como año base 1945, por ser este el año que marcó recuperación del precio internacional del café, después de la crisis de los años treintas. 
Efectivamente, el coeficiente de correlación establecido entre el indice de precios internacionales del café $y$ el indice de la superticie sembrada de ese cultivo, dió como resultado $r=0.63$ (ver Anexo $N^{2} 2$ ), lo cual significa que la asociación entre variaciones de precios y variaciones de superticie sembrada es muy importante $(63 \%)$, lo cual confirma el condicionamiento externo (via precios del mercado internacional) sobre la organización y disposición de los recursos productivos del pais, tiene también implicaciones para los movimientos de población en El Salvador y para su distribución espacial.

Las condiciones bajo las cuales ha operado el desarrollo de las relaciones capitalistas en la agricultura del pais, especialmente generadas por el eje de acumulación y concentración de las actividades de agro-exportación, han configurado tres espacios geográficos sociales:

1) Las regiones agricolas exportadoras, formadas por latifundios dedicados a la producción de café, caña de azúcar y algodón. En el caso del café sus áreas principales se localizan la cadena montañosa central y costera, que fundamentalmente comprende los departamentos de Sonsonate, Santa Ana, La Libertad, San Salvador y San Vicente. EI azúcar ocupa las partes más bajas de la cadena central e incluye la planicie costera de las partes occidental y paracentral; a los principales cultivos de algodón se ubican en la planicie costera de los departamentos de Usulután, San Miguel y San Vicente.

2) Las regiones complementarias a este eje se caracterizan por atender especialmente, tanto la demanda de productos (insumo) del sector exportador como algunos productos requeridos por los centros urbanos. En general, estas regiones están dedicadas a la cria de ganado, granos básicos y a las formas de producción artesano-doméstico, donde predominan relaciones de tipo mercantil-simple.

3) Las regiones de subsistencia satisfacen temporalmente, las necesidades de la reproducción de la fuerza de trabajo vinculada al sector exportador; por áreas de refugio para los jornaleros agricolas, las cuales en las temporadas, emigran a las regiones exportadoras en donde encuentran empleo durante, aproximadamente una cuarta parte del ano (tiempo promedio que dura la recolección de las consechas; esta población se especializa en cultivos de subsistencia (maiz, frijol, arroz, etc.), se distribuyen en todo el pais, pero fundamentalmente en las cordilleras del norte del pais (desde Chalatenango hasta La Unión y también en la planicie costera oriental.

De 10 anterior es posible afirmar que las actividades agricolas, co- 
merciales e incustriales se encuentran intersamene concentradas, desarrolladas y densarnente pobladas en todo to que es el espacb productivo de las regiones exportadoras.

La reproducab́n del modelo agro-exportados después de la crisis de los anos treintas con los culltwos de calé y cana de azuicar, consolidan a la franja meridional del país como la zona de mayor concentración de población. Es por ello, que apartir de los anos cincuenta el volumen de la población urbana de los departamentos con cultivos de exportación adquiere gran relevancia: Santa Ana, La Libertad, Sonsonate, Usulután. (Ver cuadro $\mathrm{N}^{\circ}$ 9).

\section{Cuadro Nª}

El Salvador: composiclon porcentual por zona urbana y rural, según departamento, 1950, 1961 y 1971

(Porcentajes)

\begin{tabular}{|c|c|c|c|c|c|c|c|c|c|}
\hline \multirow[b]{2}{*}{ Departamento } & \multicolumn{3}{|c|}{1950} & \multicolumn{3}{|c|}{1961} & \multicolumn{3}{|c|}{1971} \\
\hline & Total & Urbano & Rural & Total & Urbano & Rural & Total & Urbano & Rural \\
\hline Ahuachapán & 5.1 & 1.5 & 3.6 & 5.2 & 1.4 & 3.8 & 5.0 & 1.1 & 3.9 \\
\hline Santa Ana & 10.9 & 4.0 & 6.9 & 10.3 & 4.1 & 6.2 & 9.5 & 4.1 & 5.4 \\
\hline Sonsonate & 6.5 & 2.5 & 4.0 & 6.7 & 2.4 & 4.3 & 6.7 & 2.5 & 4.2 \\
\hline Chalatenango & 5.7 & 1.5 & 4.2 & 5.2 & 1.4 & 3.8 & 4.9 & 1.4 & 3.5 \\
\hline La Libertad & 7.8 & 2.7 & 5.1 & 8.1 & 2.8 & 5.3 & 8.0 & 2.8 & 5.2 \\
\hline San Salvador & 16.0 & 11.5 & 4.5 & 18.4 & 13.9 & 4.5 & 20.6 & 15.8 & 4.8 \\
\hline Cuscatlán & 4.9 & 1.2 & 3.7 & 4.5 & 1.1 & 3.4 & 4.3 & 1.2 & 3.1 \\
\hline La Paz & 5.2 & 1.8 & 3.4 & 5.2 & 1.7 & 3.5 & 5.1 & 1.5 & 3.6 \\
\hline Cabañas & 4.2 & 0.6 & 3.6 & 3.8 & 0.6 & 3.2 & 3.7 & 0.6 & 3.1 \\
\hline San Vicente & 4.7 & 1.4 & 3.3 & 4.5 & 1.4 & 3.1 & 4.3 & 1.2 & 3.1 \\
\hline Usulután & 8.7 & 2.6 & 6.1 & 8.2 & 2.3 & 5.9 & 8.3 & 2.3 & 6.0 \\
\hline San Miguel & 9.2 & 2.9 & 6.3 & 9.2 & 3.1 & 6.1 & 9.0 & 3.0 & 6.0 \\
\hline Morazán & 5.2 & 0.9 & 4.3 & 4.8 & 1.0 & 3.8 & 4.4 & 0.8 & 3.6 \\
\hline La Unión & 5.9 & 1.3 & 4.6 & 5.9 & 1.4 & 4.5 & 6.2 & 1.4 & 4.8 \\
\hline
\end{tabular}

Fuente: Anuario estadístico, 1982, tomo II, Dirección General de Estadistica y Censos, pag. 3.

En sintesis, el periodo anterior a 1950, significo una desaceleración en la velocidad de crecimiento de la población del pais. No obstante, el poco crecimiento relativo (1.04\%), fue muy desigual, ya que departamentos como San Salvador mantuvieron niveles de crecimiento poblacional muy superiores al promedio y por el contrario, departamentos como La Paz observaron un menor crecimiento poblacional (ver Anexo 
$N^{0}$ 1).

La hipotesis explicativa de acto radica para el caso de San Salvador, en su elevado crecimiento natural (naclmientos mayores que defunciones) y la atracción mioratoría que ejerce sobre la población de los otros departamentos.

Asf mismo, estos movimientos de población significaron una mayor concentración o densidad en niveles urbanos distribuidos en la franja meridional del pais; como puede observarse en el mapa $\mathrm{N}^{0} 3$ y $\mathrm{N}^{e} 4$, para 1950, las mayores densidades de población se hallan en municipios de los departamentos de San Salvador, La Libertad, Santa Ana, Sonsonate y San Miguel.

\section{Parte. Los movimlentos de población de 1950 a 1979}

Determinaclón demográflea de los movimlentos de población

\subsection{Anállsis del crecimlento de la poblaclón urbana}

La base de datos que fundamenta el análisis de este periodo fue el resultado de datos de los censos de población de 1950 y 1971; sobre los cuales se hicieron proyecciones que aparecen en los cuadros № 10 y $\mathbf{N}^{2} 11$.

En este periodo se observa un crecimiento marcado de la población urbana, su tasa de crecimiento fue superior a la tasa de crecimiento total del pais'. La explicación fundamental de estas diferencias de crecimiento radica en el fuerte movimiento migratorio de la población de zonas rurales hacia departamentos con una mayor concentración de población urbana.

En las tres décadas que comprende este periodo, los departamentos que observan una tasa de crecimiento de la poblacion, urbana igual o superior a la tasa de crecimiento general del país, son: Santa Ana, Sonsonate, Chalatenango, La Libertad, San Salvador, Cuscatlán, Cabanas y La Unión. Aproximadamente la mitad de los departamentos oel pais experimentaron una mayor concentración dela población en las áreas urbanas. Entodos los casos, a excepción del departamento de La Unión, el crecimiento urbano de la población supero el promedio de crecimiento de su respectivo departamento, (ver cuadro $N^{2} 12$ ).

1. La tasa de crecimiento de la población urban afue de 3.22; en cambio la tasa de crecimiento de la población total fue de 2.90. Esto significa que el crecimiento urbano representa el $11.1 \%$ del crecimiento global de la población del pais (ver Cuadro NN 12). 


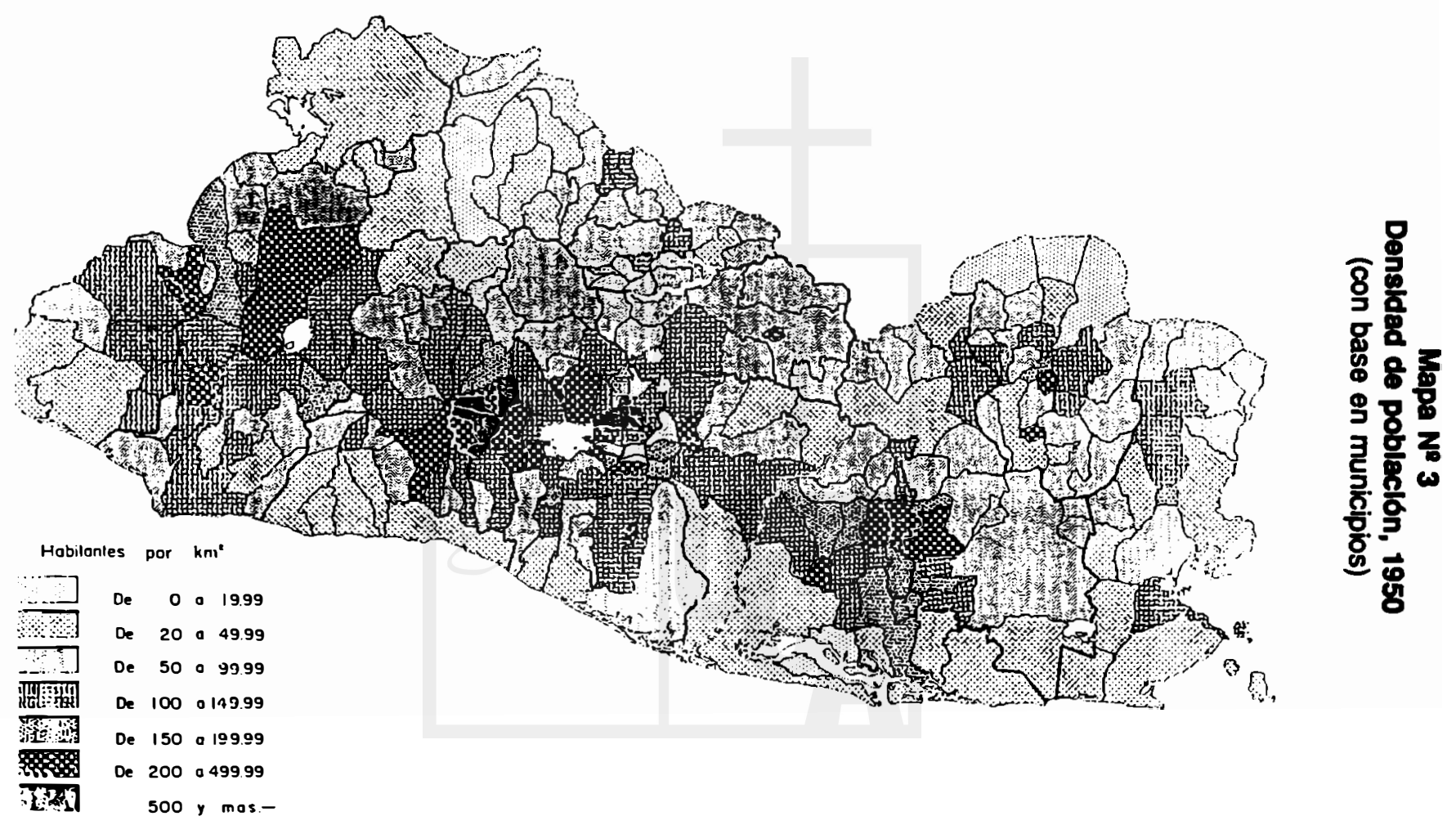

Digitalizado por Biblioteca "P. Florentino Idoate, S.J."

Universidad Centroamericana José Simeón Cañas 


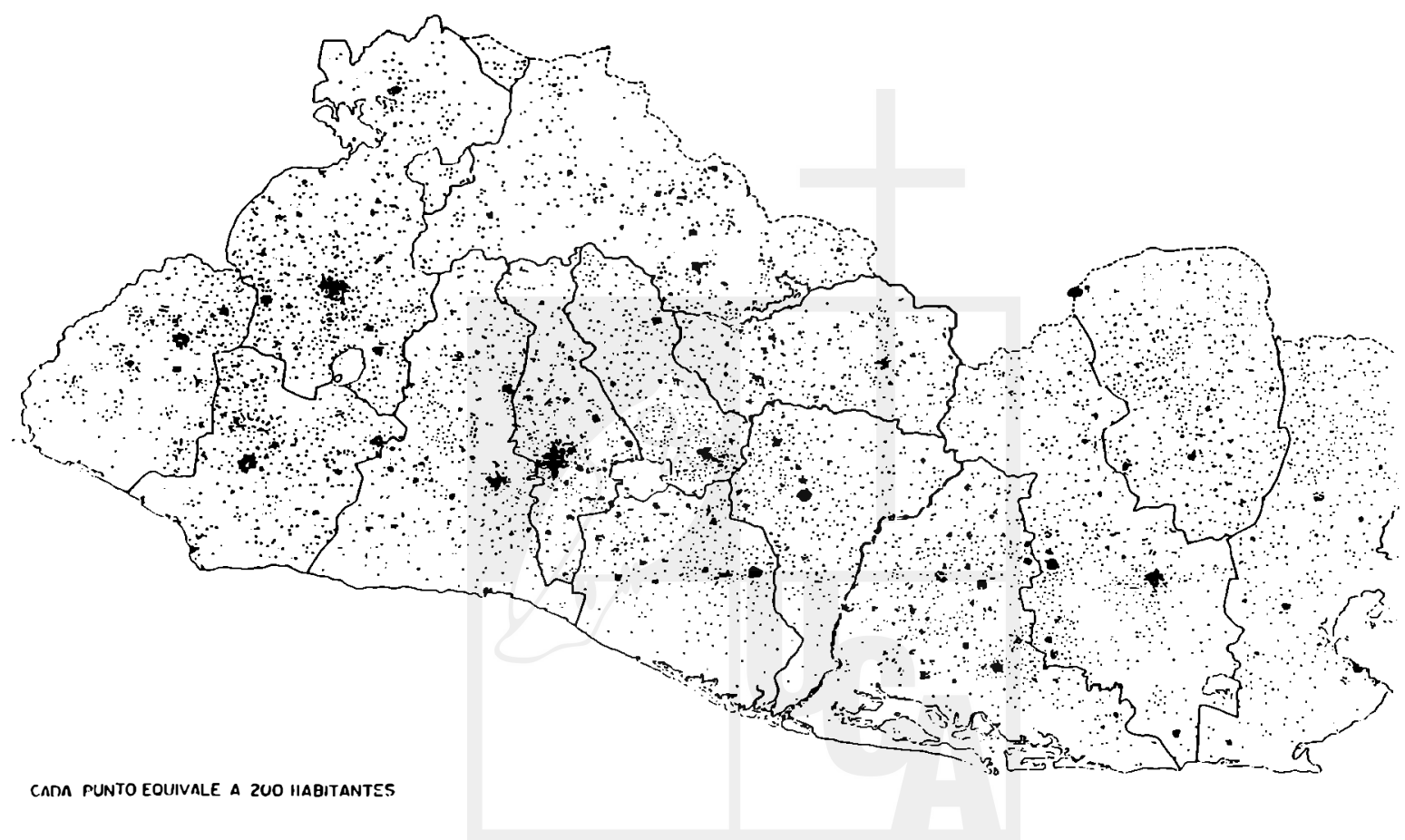

RORL NCION TOTAL I.855.917 
Cuadro NQ 10

El Salvedor. Estimación de la población y composiclón porcentual por zona urbana y rural, según depantemento, para 1979

\begin{tabular}{|l|r|r|r|r|r|r|}
\hline \multirow{2}{*}{ Departamento } & \multicolumn{3}{|c}{$\begin{array}{l}\text { (1) } \\
\text { Valor relativo (\%) }\end{array}$} \\
\cline { 2 - 6 } & Total & Urbana & Rural & \multicolumn{1}{c|}{ Total } & Urbana & Rural \\
\hline Ahuachapán & 4.6 & 0.7 & 3.9 & 204743 & 31157 & 173586 \\
Santa Ana & 8.7 & 4.0 & 4.7 & 387232 & 178038 & 209194 \\
Sonsonate & 6.6 & 2.7 & 3.9 & 293762 & 120175 & 173587 \\
Chalatenango & 4.8 & 1.5 & 3.3 & 213645 & 66764 & 146881 \\
La Libertad & 7.7 & 2.7 & 5.0 & 342722 & 120175 & 222547 \\
San Salvador & 22.3 & 17.0 & 5.3 & 992560 & 756660 & 235900 \\
Cuscatlán & 4.3 & 1.4 & 2.9 & 191391 & 62314 & 129077 \\
La Paz & 5.0 & 1.3 & 3.7 & 222547 & 57862 & 164685 \\
Cabanas & 3.8 & 0.6 & 3.2 & 169136 & 26706 & 142430 \\
San Vicente & 8.7 & 2.5 & 6.2 & 387232 & 111273 & 275959 \\
Usulután & 8.7 & 2.5 & 6.2 & 387232 & 111273 & 275959 \\
San Miguel & 8.7 & 2.7 & 6.0 & 387232 & 120175 & 267057 \\
Morazán & 4.1 & 0.5 & 3.6 & 182489 & 22259 & 160234 \\
La Unión & 6.6 & 1.3 & 5.3 & 293762 & 57862 & 235900 \\
\hline Total & 100.0 & 39.8 & 60.2 & 4450942 & 1771475 & 2679467 \\
\hline & & & & & & \\
\hline
\end{tabular}

(1) Calculados en base a fórmula del polinomio de colocación de Lagrange, para argumentos desigualmente espaciados (años calendario), la fórmula usada es: $P(X)=\Sigma L i(X)$ YI (ver Anexo N 3). 


\section{Cuadro N2 11}

El Salvador: Tasa de crecimlento (r) de la población total y de la población urbana según departamento

perlodo 1950-1071

\begin{tabular}{|l|c|c|}
\hline \multirow{2}{*}{ Departamento } & \multicolumn{2}{|c|}{ Tasa de crecirnionto (r) } \\
\cline { 2 - 3 } & Total & Urbano \\
\hline Ahuachapan & 3.02 & 1.60 \\
Santa Ana & 2.44 & 3.23 \\
Sonsonate & 3.26 & 3.11 \\
Chalatenango & 2.38 & 2.78 \\
La Libertad & 3.24 & 3.29 \\
San Salvador & 4.36 & 4.69 \\
Cuscatlán & 2.47 & 3.11 \\
La Paź & 3.02 & 2.22 \\
Cabañas & 2.49 & 3.11 \\
San vicente & 2.68 & 2.36 \\
Usulután & 2.88 & 2.51 \\
San Miguel & 3.01 & 3.28 \\
Morazán & 2.30 & 2.54 \\
La Unión & 3.36 & 3.48 \\
\hline Total & 3.11 & 3.51 \\
\hline
\end{tabular}

Fuente: Calculada en base a datos del cuadro 8.

Destacan en el mayor crecimiento urbano, el departamento de San Salvador (4.32), Cuscatlán (3.45) y Sonsonate (3.18) con niveles de crecimiento superiores o cercanos al promedio de crecimiento urbano nacional (3.22).

Las cifras anteriores son indicativas de como los movimientos migratorios del pais tienen una mayor orientación al asentamiento urbano de los departamentos mencionados. 


\subsection{Balance de las mlgraclones por departamento, según los cen- sos de 1950, 1961 y 1971.}

Hasta 1950 los flujos migratorios eran positivos para los distintos departamentos del pais, esto es explicable por la existencia, de una inmigración intemacional acumulada hasta la focha del censo, calculado en 20,191 personas equivalente al $1 \%$ de la población censada en ese ano.

Desde esa época era notable la tendencia de algunos departamentos en la captación de población procedente del resto del país entre estos figuran en primer lugar el departamento de San Salvador $(2.09 \%)$, Santa Ana (1.72\%), Chalatenango (1.13\%), Ahuachapán $(1.17 \%)$ y Cuscatlán (1.20\%), ver cuadro $N^{0} 16$.

Sin embargo, estos patrones migratorios se modificarian significativamente en el lapso de los diez anos siguientes, cuando según los resultados del censo de 1961, se marco una diferencia clara entre departamentos expulsores de población (con saldo migratorio negativo) y departamentos atractores (con saldos migratorios positivos), ver cuadro No 17.

Dentro de los atractores figuran los departamentos de Sonsonate (5.93\%), La Libertad (12.27\%), San Salvador (25.21\%) y La Unión $(2.45 \%)$.

Dentro de los departamentos expulsores destacan con mayor proporción con saldo migratorio negativo Chalatenango (-18.82\%), Cabanas $(-15.55 \%)$, San Vivente $(-15.64 \%)$ y Morazán $(-8.95 \%)$.

Es de notar como algunos de los departamentos de la zona Norte y Oriental del pais se perfilaban desde los anos 50 como zonas de expulsión de población dado el deterioro de sus condiciones económicas, sociales y culturales.

Para la siguiente década y según datos del censo de 1971 la estructura de la situación migratoria de la población censada consolidaba la tendencia de los departamentos atractores y expulsores de población. Entre los departamentos de mayor atracción migratoria seguia figurando San Salvador con $22.83 \%$, La Libertad $9.07 \%$, Sonsonate $4.59 \%$ y San Miguel $2.45 \%$.

Por el lado de los departamentos expulsores, las mayores proporciones de saldos negativos se registraron para Chalatenango con $-19.71 \%$, Cabanas con $-18.87 \%$, Usulután con $-15.41 \%$, Morazán con $-12.21 \%$, La Paz $9.45 \%$ y Cuscatlán con $8.03 \%$. 
De la comparación de las cifras de saldo migratorio negativo de los censos de 1961 y 1971, se deriva que el departamento de Chalatenango se volvió más expulsador; lo mismo puede decirse del departamento de Cabanas y del departamento de Morazán lo cual permite formular hipótesis explicativas que interpreten tales fenomenos asociados a un deterioro de las condiciones socio-económicas de sus respectivas zonas agricolas.

El departamento de Usulután, para el período 61-71 merece un comentario especial ya que su saldo migratorio negativo en 1961 $(-4.5 \%)$, creciendo más de tres veces para $1971(-15.41 \%)$. Este cambio tan importante en la estructura migratoria puede ser explicable por cambios drásticos en la estructura de empleo y en el uso de la mayor parte de la tierra agrícola como variables fundamentales para la reproducción de la existencia de las familias nurales en ese departamento.

Los cambios son fundamentalmente a la modificación del carácter de productor de granos básicos de ese departamento, para convertirse en productor algodonero, 10 cual ocurre más o menos a partir de los antos 50 y 60.

Los departamentos de la zona Occidental: Ahuachapán y Santa Ana registran saldos negativos pero en menor escala, lo cual resulta explicable debido a que el deterioro gradual de las condiciones sociales de vida, en esos departamentos es similar al promedio del país.

Un análisis que establezca la relación entre las variables: lugar de nacimiento de la población censada y el lugar de empadronamiento censal (cuadros $\mathrm{N}^{2} 19$ y 20), revelan los sentidos fundamentales de los flujos migratorios del país para un largo período (edad media de la población: entre el momento del nacimiento y el momento del levantamiento censal).

El balance entre emigraciones e inmigraciones por cada departamento, refleja las siguientes corrientes migratorias:

1) La mayor emigración o expulsión de población se desarrolla a partir de los departamentos ubicados en la zona norte y oriental del país (ver cuadro $\mathrm{N}^{2} 20$ ). Estos departamentos observan saldos migratorios negativos, lo cual indica que es mayor el número de personas que abandonan sus lugares de origen que el número de personas que llegan a residir a los mismos. Específicamente, los departamentos más típicamente expulsores de población, es decir con mayores volúmenes de saldos negativos fueron: 1) Chalatenango que observó saldos negativos con todos los departamentos, expulsó población a todos ellos. 
En este mismo gnupo, de gran expulsión se encontraban los departamentos de Cabanas y Morazán, que mantuvieron superioridad en sus emigraciones en 12 departamentos del país.

2) En un segundo grupo de mediana expulsión pueden considerarse los departamentos como San Miguel, La Unión, Usulután y San Vicente que mantuvieron saldos migratorios negativos en un rango de 7 a 120 departamentos.

Los flujos migratorios procedentes de estos departamentos estuvieron dirigidos fundamentalmente hacia las zonas occidentales $y$ centrales del país.

3) Bajo un tercer gnupo, se puede incluir a departamentos como La Paz y Cuscatlán, los cuales siendo receptores transitorios de los emigrantes de los departamentos de la zona oriental y norte del país están ubicados en el corredor geográfico que da acceso a los departamentos de San Salvador y La Libertad y a los departamentos de la zona occidental. Sin embargo, estos departamentos ofrecen un pertil de menor expulsión de población.

4) Un cuarto gnupo estaría formado por los departamentos de la zona occidental y central. Aquí destacan como departamentos de fuerte atracción migratoria: San Salvador, La Libertad y Sonsonate. El caso de Ahuachapán y Santa Ana son departamentos que atraen parte de la población que expulsan los departamentos de la zona norte y oriental del pais.

San Salvador constituye el único caso que frente a todos los departamentos del país observó saldos migratorios positivos, es decir, que recibió más población de la que emigró del mismo. Esto explica el secular flujo migratorio a la llamada zona Metropolitana de San Salvador y su acelerado crecimiento urbano.

En suma, los departamentos de San Salvador, La Libertad y Sonsonate fueron los únicos departamentos que observaron saldo migratorios positivos esto significa que el sentido fundamental de las migraciones se dirigió de los departamentos con menor nivel de urbanización y típicamente agrícolas hacia los departamentos con mayor nivel de ubanización y de predominio en actividades manufactureras, del comercio y de servicios.

Si se considera que estas migraciones son esencialmente movimientos espaciales de la población en el largo período que media entre el nacimiento y el momento del empadronamiento, es doble interpretar que ello obedece a condiciones sociales de la estructura económicoagricola y de la estructura social que propician los movimientos mi- 
gratorios en el largo período.

Las condiciones sociales de funcionamiento de la estructura económica-agricola constituye un factor importante en la respuesta a la pregunta ia qué se debe la tendencia secular a la inmigración hacia los departamentos que poseen una economia con mayores niveles de üanización?

Evidentemente, que los factores propiciatorios de la migración no son exclusivamente económicos ya que los aspectos políticos y culturales de la vida social en los departamentos de predominio agricola también contribuyen a la ocurrencia de las migraciones.

Para examinar con mayor atención cada uno de estos factores asociados a la expulsión de población de los espacios sociales de la mayoria de departamentos del país, es preciso desarrollar análisis especiales en los acápites siguientes.

\section{Anállsis de fenomenos y estructuras económlcas asocladas a las mlgraclones}

El modelo económico basado en la producción de café, necesitó profundos cambios en los patrones de tenencia y uso de la tierra en el siglo pasado y a mediados de este siglo. Con la introducción de las explotaciones capitalistas de la cana de azúcar en la meseta central, sobre todo y del algodón en la costa, los campesinos que todavia tenian ciertas facilidades para alquilar tierras o para cultivar las tierras baldias fueron siendo relegados a zonas marginales, o expulsados de los terrenos aptos para las plantaciones, también fueron disminuyendo las formas no-capitalistas, como el colonato, aunque este no desapareció del todo. Es asi como se va produciendo la proletarización del campesino, acentuando la bipolaridad latifundio-minifundio a modo de asegurar la mano de obra estacional, sin costearla todo el año y evitando en alguna medida la emigración de los campesinos a otra fuente de empleo.

Pero este proceso de explotación capitalista y de eliminación de las formas campesinas generó contradicciones. En primer lugar, provocó migraciones a la ciudad, to que implicó escasez relativa de mano de obra en el campo y en segundo lugar, hizo que el minitundio se volviera cada vez más improductivo, tanto por el desgaste del suelo y la falta de capacidad económica para reponer o mejorar la fertilidad de la tierra, como por la falta de mano de obra calificada que pueda aplicar los avances tecnológicos en una tierra que siempre suele ser marginal.

El cuadro $\mathrm{N}^{2} 21$, muestra como el colonato forma pre-capitalista que 
se incrementó con la introducción del café, experimenta un aumento entre los censos de 1950 a 1961, perlodo de inicio del cultivo masivo de algodón y comienzo de la producción cana de azúcar para la exportación. Pero la expansión de los cultivos de exportación provocan un descenso en picada en la década de los setenta como se puede apreciar en los datos del último censo (1971), reduciéndose la superficie cultivada en colonato a la tercera parte respecto a 1950 y a casi a la cuarta parte de 1961. Por lo que este tipo de relación social deja de ser una estructura de retención de población agricola subocupada.

El cuadro $N^{2} 22$ nos muestra cómo aumenta el número de familias sin tierra, que en 1961 solamente constituian el $19.3 \%$ del total, en 1971 se elevan al $31.8 \%$, y en 1975 son ya el $41.1 \%$. Por otro lado, las microfincas han ido disminuyendo, desde $37.8 \%$, a un $33.5 \%$ en 1971 , hasta el $27.8 \%$ en 1975 . Es asi como las familias que corresponden a la categoria de economia campesina (de subsistencia), que representaban el $5.4 \%$ de todas las propiedades en 1961 , bajaron al $4.1 \%$ en 1971, y al 3.6\% en 1975 (ver cuadro $N^{2} 22$ ).

Este cuadro también muestra la depauperación del habitante deagro, nos da el deterioro que se ha venido dando en las familias campesinas de los estratos más bajos: las familias sin tierra cuyo número es creciente en el tiempo, y las familias con microfincas que disminuyen proporcionalmente en el periodo al igual que las fincas subfamiliares; analizando 1975 y agnupando, tenemos que las dos primeras categorlas comprenden el $68.9 \%$ de todas las familias las cuales participan solamente con un $35.2 \%$ del ingreso, mientras que si agrupamos las otras tres categorias nos dan el $95.5 \%$ con una participación del ingreso de $60.9 \%$. Podemos observar que su porcentaje ha ido incrementándose para los anos analizados, en contraposición con la variación de su ingreso, el cual ha variado no muy significativamente; todo ello muestra una depauperación que se manifiesta progresivamente, estas familias son las que constituyen la inmensa mayoria de la población, por lo que se puede ver que la penetración y profundización del capitalismo dependiente en el agro salvadoreno ha traido consigo como primera consecuencia, un deterioro de las condiciones de vida del campesinado y como consecuencia un proceso de descampesinización, el cual provoca consecuencias, proceso de migraciones masivas de las familias campesinas hacia lugares donde ellas consideran reproducirse. 


\section{Conclusiones}

La dinámica de la población salvadorena a través de su historia resulta explicable por los hechos y estructuras económicas y sociales relacionadas con su reproducción.

Asl retrospectivamente, el descenso de la población salvadorena en los primeros anos la dominación colonial espantola, fue fundamentalmente el resultado de la descomposición de ciertas estructuras de producción de las comunidades indigenas que con gran menoscabo lograron sobrevivir. El desarrollo de los cultivos de exportación, cacao y anil en la época colonial y en los primeros anos de la formación del Estado nacional, fueron marcando en las respectivas zonas de cultivo y comercialización, la importancia demográfica de esas regiones, en las cuales se dio un mayor crecimiento natural de la población y una atracción migratoria muy fuerte.

El desarrollo de la producción cafetalera de exportación sobre el patrón de concentración de la tierra y de expansión de la renta, significó por un lado, una expulsión de la población nural hacia otras zonas rurales o urbanas, no obstante, que las zonas cafetaleras observaron un mayor crecimiento demográfico, a partir de los últimos anos del siglo pasado.

A expansión de los cultivos de algodón y cana de azúcar, se vinieron a sumar la expansión de la producción cafetalera, provocando una mayor disminución relativa de las tierras ddlicadas a cultivos de granos básicos y que funcionaban como factor productivo de subsistencia y de retención de esta población rural de migración latente. A partir de los anos cincuentas de este siglo, aumenta la expulsión de la población nural de sus zonas de origen, por ello aumenta la migración hacia zonas agrícolas de paises vecinos (Honduras fundamentalmente) y hacia zonas urbanas (mayor crecimiento de zona metropolitana).

Los años sétentas de este siglo, mostraron en fenómenos económicos y políticos: los problemas socio-demográficos que se habian generado a partir de la segunda mitad del siglo pasado. Con el conflicto Honduras-El Salvador, en 1969 y la crisis del mercado común centroamericano, se cierran las válvulas de escape para la presión demográfica de la población nural sobre los medios de producción y empleo.

Dado el conservadurismo de los régimenes políticos de la década del setenta que mantienen la estructura económica social, las tensiones y conflictos sociales aumentan. Se incrementan las luchas por el control de los recursos productivos, proliferan conflictos por las tierras, por 
empleo y salario; la crisis social se desarrolla de múltiples formas y la emioración de salvadorenos hacia América del Norte y otras regiones del mundo adquiere una gran importancia como sintoma de la crisis social del país.

\section{Cuadro Ne 12}

EI Salvador: Tasas de creclmlento (r) de la poblaclón total y de la población urbana según departamento, periodo 1950 - 1979

\begin{tabular}{|l|c|c|}
\hline \multirow{2}{*}{ Departamento } & \multicolumn{2}{|c|}{ Tasas de crecimiento } \\
\cline { 2 - 3 } & Total & Urbana \\
\hline Ahuachapán & 2.54 & 0.24 \\
Santa Ana & 2.11 & 2.91 \\
Sonsonate & 2.96 & 3.18 \\
Chalatenango & 2.30 & 2.90 \\
La Libertad & 2.86 & 2.90 \\
San Salvador & 4.10 & 4.32 \\
Cuscatlán & 2.44 & 3.45 \\
La Paz & 2.77 & 1.76 \\
Cabanass & 2.55 & 2.90 \\
San vicente & 2.42 & 1.34 \\
Usulután & 2.90 & 2.77 \\
San Miguel & 2.70 & 2.65 \\
Morazaán & 2.07 & 0.84 \\
La Unión & 3.30 & 2.90 \\
\hline Total & 2.90 & 3.22 \\
\hline
\end{tabular}

Fuente: Calculada en base a datos de cuadros Nos. 8 y 10. 


\section{Cuadro N2 13}

\section{EI Salvador: Poblackon por departamento de nacimlento empadronamlonto y saldo mlgratorlo: 1980}

\begin{tabular}{|l|c|r|r|r|}
\hline Departamento & $\begin{array}{c}\text { Departamento de } \\
\text { empadronamiento }\end{array}$ & $\begin{array}{r}\text { Departamento } \\
\text { de nacimiento }\end{array}$ & $\begin{array}{r}\text { Saldo } \\
\text { migratorio } \\
(1)-(2)\end{array}$ & $\begin{array}{r}\text { \% Saldo } \\
\text { migragorio }\end{array}$ \\
\hline Ahuachapán & 94.646 & 93.547 & 1.099 & 5.4 \\
Santa Ana & 202.455 & 198.981 & 3.474 & 17.2 \\
Sonsonate & 120.327 & 119.612 & 715 & 3.5 \\
Chalatenango & 105.859 & 104.521 & 1.338 & 6.6 \\
La Libertad & 144.004 & 142.813 & 1.191 & 5.9 \\
San Salvador & 296.452 & 290.272 & 6.180 & 30.6 \\
Cuscatlán & 90.999 & 89.914 & 1.085 & 5.4 \\
La Paz & 96.843 & 96.683 & 160 & 1.0 \\
Cabañas & 77.628 & 76.838 & 790 & 3.9 \\
San Vicente & 87.577 & 87.376 & 201 & 1.0 \\
Usulután & 162.349 & 161.440 & 909 & 4.5 \\
San Migual & 171.234 & 169.874 & 1.360 & 6.7 \\
Morazán & 96.729 & 96.052 & 677 & 3.4 \\
La Unión & 109.715 & 108.703 & 1.012 & 5.0 \\
\hline Total & 1.856 .817 & 1.839 .626 & 20.191 & 100.0 \\
\hline
\end{tabular}

Fuente Censo de población de El Salvador, 1950, pâ. 1.

\section{Cuadro Ne 14}

El Salvador: Poblaclón por departamento de nacimlento departamento de empadronamlento y saldo migratorlo: 1961

\begin{tabular}{|c|c|c|c|}
\hline Deparamento & $\begin{array}{l}\text { Departamento de } \\
\text { nacimiento }\end{array}$ & $\begin{array}{l}\text { Departamento de } \\
\text { empadronamiento }\end{array}$ & $\begin{array}{l}\text { Saldo Migratorio } \\
\text { (1) - (2) }\end{array}$ \\
\hline $\begin{array}{l}\text { Ahuachapen } \\
\text { Santa Ana } \\
\text { Sonsonate } \\
\text { Chalatenango } \\
\text { La Libentad } \\
\text { San Salvador } \\
\text { Cuccailan } \\
\text { La Paz } \\
\text { Cabahias } \\
\text { San vicents } \\
\text { Usulutin } \\
\text { San Miguel } \\
\text { Moraztn } \\
\text { La Unión }\end{array}$ & $\begin{array}{l}135.461 \\
209.832 \\
157.017 \\
150.783 \\
178.500 \\
346.432 \\
125.482 \\
138.888 \\
108.929 \\
130.591 \\
216.274 \\
242.274 \\
130.076 \\
144.421\end{array}$ & $\begin{array}{r}130.710 \\
259.155 \\
166.932 \\
126.897 \\
203.480 \\
463.228 \\
113.042 \\
130.654 \\
94.590 \\
112.920 \\
207.061 \\
231.821 \\
119.381 \\
148.108\end{array}$ & $\begin{array}{rr}- & 4.751 \\
- & 10.677 \\
+ & 9.915 \\
- & 23.886 \\
+ & 24.880 \\
+ & 116.796 \\
- & 12.440 \\
- & 8.234 \\
- & 14.339 \\
- & 17.671 \\
- & 9.213 \\
- & 10.453 \\
- & 10.695 \\
+ & 3.637\end{array}$ \\
\hline Total & 2.475 .010 & 2.507 .970 & 29.959 \\
\hline
\end{tabular}

Fuent: Segundo Ceneo de Pobleción de El Salvedor, 1961. 


\section{Cuedro Ne 15}

EI Salvedor: Poblecibn por depariemento de necimbito departamento de empedronamlento y saldo migratorlo: 1971

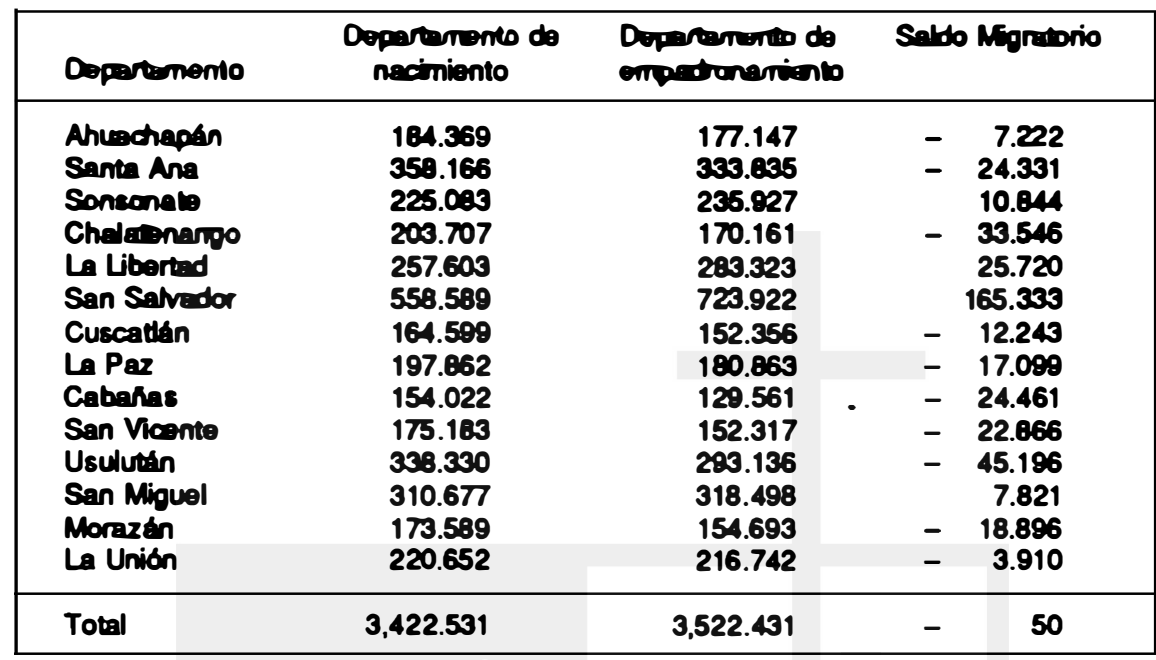

Fuento: El Salvador, Dirección General de Estadistica y Censos, IV Conso Nacional de Población 1971, (27 de junio de 1971), Vol. I, Cuadro No 24.

\section{Cuadro Ne 16}

El Salvador: Estructura de la situación mlagratorla de la población censada en $\mathbf{1 9 5 0}$

\begin{tabular}{|l|c|c|c|}
\hline Departamento & $\begin{array}{c}\text { Población consada } \\
\text { en } 1950\end{array}$ & $\begin{array}{c}\text { Población nacida } \\
\text { en cada departamento }\end{array}$ & $\begin{array}{c}\text { Población inmigrante } \\
\text { a cada departamento }\end{array}$ \\
\hline Ahuachapán & 100.00 & 98.83 & 1.17 \\
Santa Ana & 100.00 & 98.28 & 1.72 \\
Sonsonate & 100.00 & 99.40 & 0.60 \\
Chalatenango & 100.00 & 98.87 & 1.13 \\
La Libertad & 100.00 & 99.17 & 0.83 \\
San Salvador & 100.00 & 97.91 & 2.09 \\
Cuscattán & 100.00 & 98.80 & 1.20 \\
La Paz & 100.00 & 99.83 & 0.17 \\
Cabañas & 100.00 & 98.98 & 1.02 \\
San Vicennte & 100.00 & 99.77 & 0.23 \\
Usulután & 100.00 & 99.44 & 0.56 \\
San Miguel & 100.00 & 99.21 & 0.79 \\
Morazén & 100.00 & 99.30 & 0.70 \\
La Unión & 100.00 & 99.07 & 0.93 \\
\hline Total & 100.00 & 98.91 & 1.09 \\
\hline
\end{tabular}

Fuent: Cuadro № 13. 


\section{Cuadro Ne 17}

El Salvador: Estructura de la shuación mlagratorla de la poblaclón censada en 1961

\begin{tabular}{|l|c|c|c|}
\hline Departamento & $\begin{array}{c}\text { Departamento de } \\
\text { nacimionto }\end{array}$ & $\begin{array}{c}\text { Departamento de } \\
\text { empedronamiento }\end{array}$ & Seldo migratorio \\
\hline Ahuachapan & 100.00 & 103.63 & -3.63 \\
Santa Ana & 100.00 & 104.11 & -4.11 \\
Sonsonate & 100.00 & 94.06 & 5.83 \\
Chalatenanoo & 100.00 & 118.82 & -18.82 \\
La Libertad & 100.00 & 87.72 & 12.27 \\
San Salvador & 100.00 & 74.78 & 25.21 \\
Cuscaután & 100.00 & 111.00 & -11.00 \\
La Paz & 100.00 & 106.30 & -6.30 \\
Cabahas & 100.00 & 115.15 & -15.15 \\
San Vicente & 100.00 & 115.64 & -15.64 \\
Usulután & 100.00 & 104.50 & -4.50 \\
San Miguel & 100.00 & 104.50 & -4.50 \\
Morazán & 100.00 & 108.95 & 8.95 \\
La Unión & 100.00 & 97.54 & 2.45 \\
\hline Total & 100.00 & 98.68 & 1.31 \\
\hline
\end{tabular}

Fuent: Cuadro № 14.

Cuadro N2 18

El Salvador: Estructura de la shuación mlagratorla de la poblaclón censada en 1971

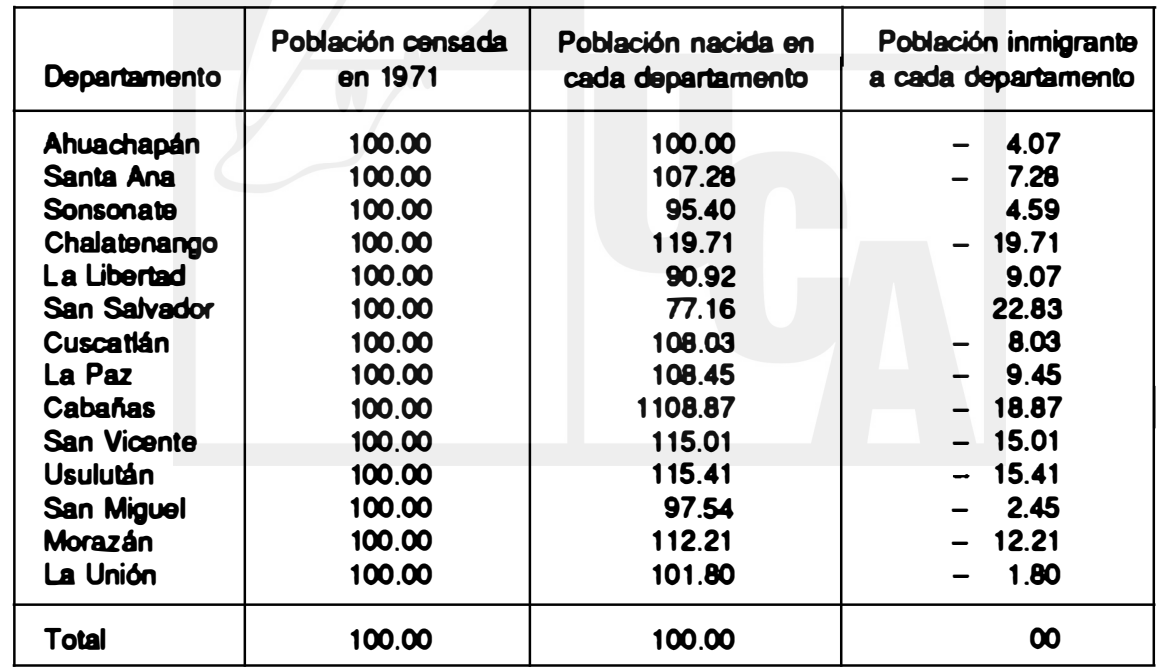

Fuent: Cuadro № 15. 
Cuadro No. 19

El salvador: Población por departamento de nacimlento

y según departamento de enumeración de nacimlento

\begin{tabular}{|c|c|c|c|c|c|c|c|c|c|c|c|c|c|c|c|}
\hline Depariamento & Total & $\begin{array}{l}\text { Ahue- } \\
\text { chapan }\end{array}$ & $\begin{array}{l}\text { Sama } \\
\text { Ana }\end{array}$ & $\begin{array}{c}\text { Sonso } \\
n \in 10\end{array}$ & $\begin{array}{l}\text { Chala- } \\
\text { tenanoo }\end{array}$ & La L- & San Sat & Cusca & La Pezz & $\begin{array}{c}\text { Caba- } \\
\text { nas }\end{array}$ & $\begin{array}{c}\operatorname{sen} u \\
\operatorname{con} \theta\end{array}$ & $\begin{array}{c}\text { San } \mathbf{M}_{\mathrm{j}}- \\
\text { guel }\end{array}$ & $\begin{array}{l}\text { Usulu- } \\
\text { tán }\end{array}$ & $\begin{array}{l}\text { Mora- } \\
\text { zán }\end{array}$ & La Union \\
\hline Tolal & $1,522.481$ & 164.369 & 358.166 & 225.083 & $200 . \pi 07$ & 257.600 & 558.580 & 164.560 & 197.962 & 154.022 & 175.160 & 338.330 & 310.677 & 173.589 & 220.652 \\
\hline Ahuachapén & 177.147 & 160.092 & 4.635 & 3.653 & 1.750 & 2.280 & 1.737 & 180 & 580 & $\infty \infty$ & 468 & 541 & 900 & 152 & 222 \\
\hline Senta Ana & 333.835 & 8.571 & 301.578 & 6.352 & 3.240 & 4.097 & 5.413 & 625 & 240 & 650 & 814 & 1.406 & 1.464 & 347 & 339 \\
\hline Sonsonate & 235.927 & 7.102 & 11.228 & 180.464 & 3.756 & 7.004 & 5.220 & 785 & 1.658 & 1.848 & 1.531 & $1.2 \pi$ & 2.177 & 285 & 612 \\
\hline Chalatenango & 170.161 & 145 & 1.680 & 358 & 163.817 & 605 & 1.956 & 655 & 182 & 335 & 143 & 172 & 109 & 47 & 103 \\
\hline La Libertad & 283.323 & 1.636 & 12.760 & 7.092 & 7.000 & 215.127 & 17.231 & 3.528 & 3.801 & 4.973 & 3.557 & 2.114 & 2.682 & 692 & 916 \\
\hline San Salvador & 723.922 & 7.485 & 23.009 & 14.732 & 19.571 & 25.714 & 508.705 & 18.500 & 24.560 & 11.210 & 17.402 & 18.826 & 22.413 & 5.226 & 8.553 \\
\hline Cuscatlán & 152.356 & 152 & 574 & 341 & 2.125 & 1.052 & 5.105 & 136.480 & 1.258 & 1.967 & 1.689 & 495 & 683 & 155 & 280 \\
\hline La Paz & 180.663 & 247 & 604 & 476 & 732 & 1.132 & 4.780 & 1.548 & 160.347 & 1.240 & 4.859 & 1.212 & 3.032 & 294 & 324 \\
\hline Cabanes & 129.561 & 53 & 155 & 178 & 565 & 239 & 923 & 871 & 250 & 124.375 & 897 & 285 & 350 & 64 & 97 \\
\hline San Vicente & 152.317 & e4 & 245 & 265 & 325 & 331 & 1.847 & 730 & 2.141 & 3.202 & 138.085 & 1.059 & 2.395 & 199 & 291 \\
\hline Usulután & 293.136 & 287 & 635 & 376 & 457 & 407 & 2.778 & $2 \pi$ & 1.517 & 2.146 & 3.016 & 13.650 & 264.254 & 1.257 & 2.000 \\
\hline San Miguel & 318.498 & 182 & 702 & 404 & 280 & 391 & 2.490 & 281 & 401 & 464 & 1.001 & 287.444 & 8.475 & 8.856 & 6.989 \\
\hline Morazán & 154.693 & 39 & 76 & 71 & 65 & $\pi$ & 359 & 40 & 51 & 47 & 56 & 1.725 & 329 & 150.476 & 1.280 \\
\hline La Unión & 216.742 & 73 & 246 & 120 & 191 & 175 & 878 & 127 & 173 & 388 & 445 & 0.117 & 1.424 & 5.539 & 198.846 \\
\hline
\end{tabular}

Fuente: El Salvador, Dirección General de Estadística y Censos, IV Censo Nacional de Población 1971, (27 junio de 1971), Vol. I, Cuadro N2 24 pp. 264-331

Nota: Los datos analizados en forma horizontal permiten detectar el origen de la población que habita el departamento de San Salvador, o de cualquier otro departamento que sea considerado.

Digitalizado por Biblioteca "P. Florentino Idoate, S.J."

Universidad Centroamericana José Simeón Cañas 


\section{Cuadro Ne 20}

El Salvador: Saldos migratorlos por departamentos de nacimlento y según departamentos de empadronamlento 1971

\begin{tabular}{|c|c|c|c|c|c|c|c|c|c|c|c|c|c|c|}
\hline Deparamento & $\begin{array}{l}\text { Ahua- } \\
\text { chapán }\end{array}$ & $\begin{array}{l}\text { Santa } \\
\text { Ana }\end{array}$ & $\begin{array}{l}\text { Sonso- } \\
\text { nate }\end{array}$ & $\begin{array}{l}\text { Chala- } \\
\text { tenango }\end{array}$ & $\begin{array}{l}\text { La Li- } \\
\text { bertad }\end{array}$ & $\begin{array}{l}\text { San Sat } \\
\text { vedor }\end{array}$ & $\begin{array}{c}\text { Cusca- } \\
\text { tan }\end{array}$ & La Paz & $\begin{array}{c}\text { Caba- } \\
\text { has }\end{array}$ & $\begin{array}{c}\text { San Vi- } \\
\text { conte }\end{array}$ & $\begin{array}{l}\text { Usulu- } \\
\text { tán }\end{array}$ & $\begin{array}{l}\text { San M- } \\
\text { guel }\end{array}$ & $\begin{array}{l}\text { Mora- } \\
\text { zán }\end{array}$ & La Unión \\
\hline Ahuachapán & & 1,036 & 3,250 & $-1,613$ & 656 & 5,748 & -47 & -321 & -756 & -384 & -621 & -359 & -133 & -149 \\
\hline Santa Ana & $-1,936$ & & $4,8 \pi$ & $-1,560$ & 8,681 & 17,626 & -51 & -345 & -495 & -569 & -829 & -704 & -271 & -266 \\
\hline Sonsonate & $-3,250$ & $-4,8 \pi 7$ & & $-3,398$ & 88 & 8.512 & -424 & $-11,180$ & $-1,669$ & $-1,266$ & $-1,801$ & -875 & -214 & -492 \\
\hline Chalatenango & $-1,613$ & $-1,560$ & 3,399 & & 6,401 & 17,615 & 1,490 & 550 & 230 & 182 & 268 & 127 & 18 & 88 \\
\hline La Libertad & -656 & $-8,681$ & -88 & $-6,401$ & & 8,463 & $-2,476$ & $-2,669$ & $-4,734$ & $-3,226$ & $-2,195$ & $-1,723$ & -613 & -741 \\
\hline San Salvador & _5,748 & $-17,626$ & $-8,512$ & $-17,615$ & $-8,483$ & & $-13,493$ & $-19,780$ & $-10,287$ & $-15,553$ & $-19,635$ & $-16,327$ & $-4,867$ & $-7,475$ \\
\hline Cuscastlán & 47 & 51 & 424 & $-1,490$ & 2,476 & 13,493 & & 290 & $-1,206$ & -951 & -407 & -214 & -115 & 153 \\
\hline La Paz & 321 & 345 & 1,180 & $-\mathbf{5 5 0}$ & 2,689 & 19.780 & -290 & & -990 & $-2,718$ & $-1,515$ & -731 & -243 & 151 \\
\hline Cabahas & 756 & 495 & 1,669 & -230 & 4,734 & 10,287 & 1,206 & 998 & & 2,205 & 1,788 & 179 & -17 & 291 \\
\hline San Vicente & 384 & 569 & 1,266 & -192 & 3,226 & 15,553 & 915 & 2,718 & $-2,205$ & & 621 & -28 & -143 & 154 \\
\hline Usulután & 621 & 829 & 1,801 & -268 & 2,195 & 19,635 & 407 & 1,515 & $-1,788$ & -621 & & $-5,175$ & -928 & -576 \\
\hline San Miguel & 359 & 704 & 875 & -127 & 1,723 & 16,327 & 214 & 731 & -179 & 28 & 5,175 & & $-7,131$ & 1,128 \\
\hline Morazán & 113 & 271 & 214 & -18 & 613 & 4,867 & 115 & 243 & 17 & 143 & 928 & 7,131 & & 4,259 \\
\hline La Unión & 149 & 266 & 492 & -88 & 741 & 7,475 & 153 & 151 & -291 & -154 & 576 & $-1,128$ & $-4,259$ & \\
\hline
\end{tabular}

Fuente: Cuadro № 20.

Bota: Los dastos analizados por columna expresan que un valor negasivo significa un mayor número de salidas que entradas a ese departamento (mayores emigraciones del departamento de nacimiento) 
Cuadro Ne 21

Número de explotaclones y superficle trabajadora por reglmen de tenencla El Salvador 1961-1971 (superficle en héctareas)

\begin{tabular}{|c|c|c|c|c|c|c|c|c|c|c|}
\hline \multirow[b]{3}{*}{$\begin{array}{l}\text { Regimen de } \\
\text { renencia }\end{array}$} & \multirow{2}{*}{\multicolumn{2}{|c|}{1950}} & \multirow{2}{*}{\multicolumn{2}{|c|}{1961}} & \multirow{2}{*}{\multicolumn{2}{|c|}{1971}} & \multirow{2}{*}{\multicolumn{2}{|c|}{$\begin{array}{c}\% \\
\text { Variac. } 1950-71\end{array}$}} & \multirow{2}{*}{\multicolumn{2}{|c|}{$\begin{array}{c}\% \\
\text { Variac. } 1961-71\end{array}$}} \\
\hline & & & & & & & & & & \\
\hline & $\begin{array}{l}\text { No. } \\
\text { Explot. }\end{array}$ & Superificie & $\begin{array}{l}\text { No. } \\
\text { Explot. }\end{array}$ & Superficie & $\begin{array}{l}\text { No. } \\
\text { Explot. }\end{array}$ & Supericie & $\begin{array}{l}\text { No. } \\
\text { Explot. }\end{array}$ & Superficie & $\begin{array}{l}\text { No. } \\
\text { Explot. }\end{array}$ & Superticie \\
\hline - Propiedad & - & - & 89.918 & $1,225.221$ & 108.014 & $1,105.394$ & - & - & 20.1 & -9.8 \\
\hline - Arrendamiento & 32.945 & 79.382 & 43.457 & 78.887 & 76.256 & 104.662 & 131.5 & 31.8 & 75.5 & 32.7 \\
\hline - Mixio & - & - & 29.805 & 123.319 & 36.345 & 133.588 & - & - & 21.9 & 8.3 \\
\hline $\begin{array}{c}\text { - Otras formas } \\
\text { de Posesión }\end{array}$ & - & - & 7.947 & 109.935 & 33.235 & 97.960 & - & - & 318.2 & -10.0 \\
\hline - Colonato & 33.384 & 31.837 & 55.769 & 44.076 & 17.018 & 10.290 & 49.0 & -67.7 & -69.5 & -76.7 \\
\hline Total & - & - & 226.896 & 1.581 .428 & 270.868 & $1,471.894$ & - & - & 19.4 & -8.2 \\
\hline
\end{tabular}

Fuente:Primer y Tercer Censo Nacional Agropecuario 1950 y 1971. 
Cuadro Ne 22

Porcentaje de tamllias y su Ingreso respecto al PIB

agropecuarlo (Preclos de 1975)

\begin{tabular}{|l|r|r|r|r|r|r|}
\hline \multirow{2}{*}{} & \multicolumn{2}{|c|}{1961} & \multicolumn{2}{c|}{1971} & \multicolumn{2}{c|}{1975} \\
\cline { 2 - 7 } \% Fam. & $\begin{array}{l}\text { Partici- } \\
\text { pación } \\
\text { ingreso }\end{array}$ & \% Fam. & $\begin{array}{l}\text { Particl- } \\
\text { pación } \\
\text { ingreso }\end{array}$ & \% Fam. & $\begin{array}{l}\text { Partici- } \\
\text { pación } \\
\text { ingreso }\end{array}$ \\
\hline Familias sin & 19.8 & 9.0 & 31.8 & 15.8 & 41.1 & 15.4 \\
tierras & 19.8 & 21.9 & 33.5 & 20.6 & 27.8 & 16.8 \\
Microfincas & 37.8 & 28.9 & 29.8 & 27.5 & 26.6 & 27.7 \\
Sub-fmailias & 35.4 & 11.4 & 4.1 & 10.5 & 3.6 & 11.4 \\
Familiares & 5.4 & 11.4 & 11.5 & 0.7 & 12.2 \\
Multifamilia- \\
res medianas & 1.2 & 12.8 & 0.6 & 11.5 \\
Multifamilia- & 0.4 & 16.0 & 0.2 & 14.1 & 0.2 & 15.2 \\
res grandes & 0.4 & 100.0 & 100.0 & 100.0 & 100.0 & 100.0 \\
Total & 100.0 & 10.0 & \\
\hline
\end{tabular}

Fuente: OSPA - MAG. Capitulo sobre el ingreso agropecuario.

\section{Cltas}
1. $+\sqrt{\frac{N t}{N_{0}}-1}$; En donde:
$r=$ tasa de crecimiento anual
$t=$ periodo $t-0$
$\mathrm{Nt}$ - población al final del período $\mathrm{t}-0$
No - Población al inicio al período $\mathrm{t}$ - 0

2. Browning, David. El Salvador la Tierra y El Hombre. Ministerio de Educación, El Salvador, 1975, págs. 30-48.

3. El Salvador. "Prontuario Municipal", depantamento de La Libentad. Ed. Epoca, San Salvador, 1988, p-p: 9-17.

4. Cr. Browning, David, Op. Cit. p-o: 99-115.

5. Menjivar, Rafael. Acumulación Originaria y Desarrollo del Capitalismo en EI Salvador. Ed. Universitaria Centro América, (EDUCA), 1980, pág. 99.

6. Castro, Juan Francisco. Dirección General de Estadistica. "Geografla Elemental de El Salvador". demografla, El Salvador. 1905.

7. Browning, Op. Cit. Pág. 247.

8. Ibid. 
9. $r=\sqrt[t]{\frac{S t}{S O}-1}$

En donde:

St - Superficie sembrada al perlodo t y

So - Superticie sembra al inicio del perlodo.

\section{Anoxo Ne 1}

El Salvedor: Taaaa de creclmbento (r) de la poblackón sogún departamento, porlodoo: 1982-1930 y 1030-1950

(Porcentajes)

Departamento

Ahuachapán*

Sonsonate*

Santa Ana"

La Libertad"

Chalatenango

San Salvador*

Cuscatlán

Cabahas

San Vicente

La Paz

Usulután

San Miguel•

Morazán

La Unión
$1982-1930$

(r) 1
$1930-1950$

1.07

1.12

1.57

1.20

1.49

2.44

0.53

1.66

0.81

0.62

1.52

1.56

1.49

2.25

Fuento: 1. Barón Caatro Op. Cit. Págs. 488 y 508.

2. DIGESTYC. Anuarb Estadiatlcoa U. 2. 1982, pág. 2 Ajustados con datos de Cuadro Ne 5

$$
r=\sqrt[+]{\frac{N^{+}}{N^{0}}-1 i}
$$

- Departamentos con mayor desarrollo del cultivo de café. 


\section{Anoxo NP 2}

Cállculo del cooflelente de corroleclón por el motodo productomomento de Karl Pearson, para datos del perlodo 1931 - 1954

$$
r=\frac{n \sum X Y-\left(\sum X\right)\left(\sum Y\right)}{\sqrt{\left[n \sum X^{2}-\left(\sum X\right)^{2}\right]\left[n \sum Y^{2}-(W Y)^{2}\right]}}
$$

Sea "X" el índice de precios de caf́́

\begin{tabular}{|c|c|c|c|c|c|}
\hline Año & 1931 & 1933 & 1945 & 1948 & 1951 \\
\hline$x$. & $\begin{array}{c}49.1 \\
100 .\end{array}$ & $\begin{array}{l}42.9 \\
102\end{array}$ & $\begin{array}{l}100 . \\
118.7\end{array}$ & $\begin{array}{l}185.3 \\
138.8\end{array}$ & $\begin{array}{l}356.5 \\
121.6\end{array}$ \\
\hline
\end{tabular}

Sea "Y" el lindice de superficie sembrada de caf́́.

\begin{tabular}{|c|c|c|c|c|c|}
\hline$N$ & $X$ & $Y$ & $X Y$ & $X^{2}$ & $Y^{2}$ \\
\hline 1 & 49.1 & 100 & 4910 & 2410.81 & 10000 \\
\hline 2 & 42.9 & 102 & 4375.8 & 1840.41 & 10404 \\
\hline 3 & 100. & 118.7 & 11870 & 10000 & 14130.08 \\
\hline 4 & 185.3 & 138.8 & 25719.64 & 34336.09 & 19265.44 \\
\hline 5 & 356.5 & 121.6 & 43350.4 & 127092.25 & 14786.56 \\
\hline 6 & 392.6 & 128.6 & 50488.36 & 154134.76 & 16537.96 \\
\hline & 1126.4 & 709.7 & 140714.2 & 329814.32 & 85124.04 \\
\hline
\end{tabular}

$$
\begin{aligned}
& r=\frac{6(140714.2)-[(1126.4)(70.7)]}{\left[6(329814.32)-(1126.4)^{2}\right]} \\
& \text { [6 }(85124.04)-(709.7)^{2}
\end{aligned}
$$

$$
\begin{aligned}
& r=\frac{44879.12}{70856.02925} \\
& r=0.63338 \\
& r=0.63 \quad 63 \%
\end{aligned}
$$




\section{Anoxo No 3}

\section{n \\ Polonomlo de colocación de lagrande: $P(X)=\sum_{I=0} L I(X)$ VI}

En donde $P(X)$ : es el punto enla función de población para el año " $X "$; $L i(X)$ es la función multiplicadora de Lagrange

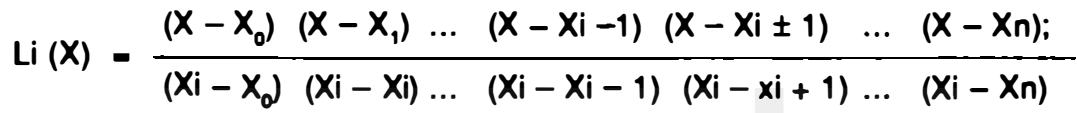

Que tiene las propiedades

$\mathrm{Li}(X k)=0$ Para $k \neq \mathrm{i}, \mathrm{Li}(X i)=1$

Que representa el polinomio de colocación, o sea P (Xk) - Yk;

on forma compacta:

$\operatorname{Li}(X)=\pi(X) /[(X-X i) \quad(X i)]$,

la función intimamente relacionada con la anterior

$F k(X)=\pi_{i \neq k}^{\pi}(X-X i)$

Se predice la composición porcentual de la población salvadoreña para cada departamento, para el año de 1979, siendo los argumentos 1950, 1961 y 1971.

La estimación se hace por la ausencia de datos ajustados a nivel de departamento para ese año y en consideración de que los factores demográficos y sociales asociados a la dinámica de población mantienen su influencia y distribución secular en el período 1950 - 1979.

Ej. Sea $P(X)$ : composición porcentual de la población del departamento de Ahuachapán para 1979.

Sea XI: el año 0 argumento al cual están asociados los datos de población; i - 0, 1, 2, que corresponden a 1950, 1961 y 1971, respectivamente, $X=1979$.

Sea Yi: el valor de la función de población apra cada i.

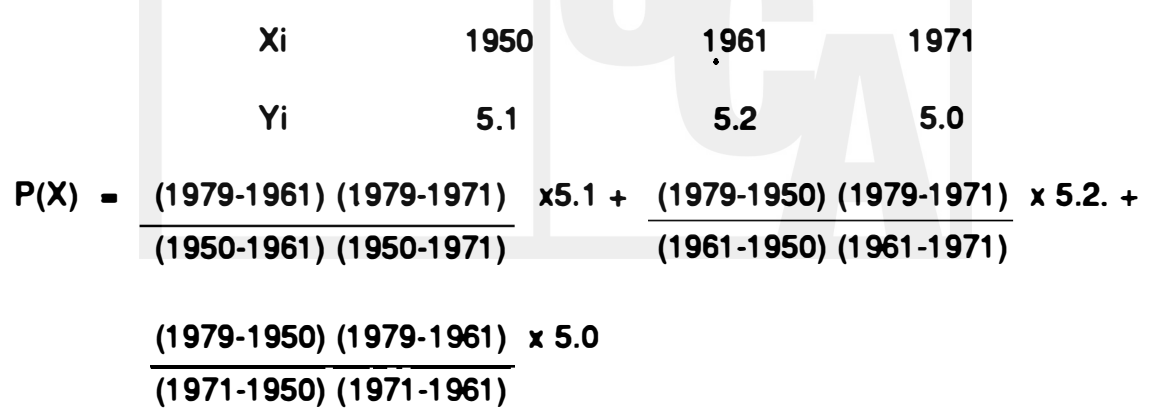

$P(X)=4.6 \% \quad P(X)=4.6 \% \quad 317 \pm 10.96$ 
Clr. Scheid, Francis, "Anélisis Numbérico", Mc Graw - Hill, Móxico 1977, cap. 8 y 12.

2) Calculada on base a estimación de Direcolón de Pobleclón de El Salvador (1986) y para 1979 la pobleción total del pals fue: 4,450,942. 